\title{
Hemispheric differences in the mesostriatal dopaminergic system
}

\author{
Ilana Molochnikov and Dana Cohen* \\ The Leslie and Susan Gonda Multidisciplinary Brain Research Center, Bar-Ilan University, Ramat-Gan, Israel
}

\section{Edited by:}

Ahmed A. Moustafa, University of

Western Sydney, Australia

Reviewed by:

Rachel Tomer, University of Haifa,

Israel

Reuben Ruby Shamir, Case Western

Reserve University, USA

*Correspondence:

Dana Cohen, The Gonda Brain

Research Center, Bar Ilan University,

Building number 901, Ramat Gan

52900, Israel

e-mail:danacoh@gmail.com
The mesostriatal dopaminergic system, which comprises the mesolimbic and the nigrostriatal pathways, plays a major role in neural processing underlying motor and limbic functions. Multiple reports suggest that these processes are influenced by hemispheric differences in striatal dopamine (DA) levels, DA turnover and its receptor activity. Here, we review studies which measured the concentration of DA and its metabolites to examine the relationship between DA imbalance and animal behavior under different conditions. Specifically, we assess evidence in support of endogenous, inter-hemispheric DA imbalance; determine whether the known anatomy provides a suitable substrate for this imbalance; examine the relationship between DA imbalance and animal behavior; and characterize the symmetry of the observed inter-hemispheric laterality in the nigrostriatal and the mesolimbic DA systems. We conclude that many studies provide supporting evidence for the occurrence of experience-dependent endogenous DA imbalance which is controlled by a dedicated regulatory/compensatory mechanism. Additionally, it seems that the link between DA imbalance and animal behavior is better characterized in the nigrostriatal than in the mesolimbic system. Nonetheless, a variety of brain and behavioral manipulations demonstrate that the nigrostriatal system displays symmetrical laterality whereas the mesolimbic system displays asymmetrical laterality which supports hemispheric specialization in rodents. The reciprocity of the relationship between DA imbalance and animal behavior (i.e., the capacity of animal training to alter DA imbalance for prolonged time periods) remains controversial, however, if confirmed, it may provide a valuable non-invasive therapeutic means for treating abnormal DA imbalance.

Keywords: dopamine, laterality, striatum, side preference, VTA, nucleus accumbens

\section{INTRODUCTION}

There is a general consensus regarding cerebral dominance and hemispheric specialization in the human brain in which the right hemisphere is dominant for analyzing complex visuo-spatial relationships and for the perception and expression of emotions, whereas language is represented in the left hemisphere (Kimura and Archibald, 1974; Gazzaniga, 1995; Davidson and Kenneth, 2004; Fox and Reed, 2008; Gotts et al., 2013). Healthy subjects display asymmetries in the DA system, which in humans have been associated, for example, with lateralized motor performance and hand preference (Bracha et al., 1987; De La Fuente-Fernandez et al., 2000; Mohr and Bracha, 2004). Pathological DA asymmetries occur in neuropsychiatric and neurodegenerative disorders such as schizophrenia, depression, and Parkinson's disease (Peterson et al., 1993; Seibyl et al., 1995; Gruzelier, 1999; Hietala et al., 1999; Van Dyck et al., 2002; Hsiao et al., 2003, 2013). Interhemispheric imbalance in DA concentration and its metabolites has been described in the rodent mesostriatal system and in related structures such as prefrontal cortex (PFC), Entorhinal cortex (EC) and the hippocampus (Glick et al., 1982; Schneider et al., 1982; Denenberg and Rosen, 1983; Drew et al., 1986; Fride and Weinstock, 1987; Nowak, 1989; Rodriguez et al., 1994; Becker,
1999; Hietala et al., 1999; Thiel and Schwarting, 2001; Van Dyck et al., 2002; Silva et al., 2007; Vernaleken et al., 2007; Cannon et al., 2009; Martin-Soelch et al., 2011; Hsiao et al., 2013). This DA imbalance in the mesostriatal system has been associated with a variety of motor and cognitive aspects of behavior among which are spatial performance such as side preference in a $\mathrm{T}$ maze or during lever-press (Zimmerberg et al., 1974; Glick et al., 1981; Castellano et al., 1987), locomotor activity (Glick and Ross, 1981; Glick et al., 1988; Cabib et al., 1995; Nielsen et al., 1997; Budilin et al., 2008), difference in sensitivity to intracranial selfstimulation, motivation, responsiveness to stress, and appetitive and aversive stimuli (Glick et al., 1981; Carlson et al., 1991, 1993; Besson and Louilot, 1995; Sullivan and Gratton, 1998; Berridge et al., 1999; Sullivan and Dufresne, 2006; Fox and Reed, 2008; Tomer et al., 2008, 2014; Laplante et al., 2013).

In this review, we address the midbrain DA system functionality by examining the laterality of the mesostriatal system in populations of animals as reflected in DA imbalance across hemispheres. To do so, we specify the type, origin and destination of primarily midbrain DA neurons, review evidence supporting DA related hemispheric laterality as assessed by measuring DA levels and its metabolite dihydroxyphenylacetic acid (DOPAC), 
examine correlations between DA imbalance and spatial and cognitive biases in animal behavior, and finally, we discuss the ways in which these correlations are altered in response to unilateral and systemic biochemical intervention and behavioral manipulation. We particularly ask whether or not manipulations generate a symmetrical effect across hemispheres (i.e., whether a unilaterally applied manipulation generates a mirror image of the effect generated by applying that manipulation to the other hemisphere). The search for papers was done using relevant key words such as asymmetry, laterality, DA, ventral tegmental area (VTA), substantia nigra ( $\mathrm{SN}$ ), striatum, nucleus accumbens (NAc), PFC, medial forebrain bundle (MFB), 6-hydroxydopamine (6-OHDA), unilateral, left, right, inter hemispheric, mesostriatal, mesolimbic, nigrostriatal, affective, limbic, etc. Papers were selected irrespective of results if reported data comprised left/right information without collapsing them across hemispheres.

\section{ANATOMY AND CONNECTIVITY}

The two prime dopaminergic fiber groups, the A9 and A10, are located in the ventral midbrain (Dahlstroem and Fuxe, 1964). The A10 group is the largest group of DAergic cells in the ventral midbrain tegmentum which is located for the most part in the VTA. The A10 group represents about two thirds ( $~ 65 \%)$ of VTA cell population. In addition, the VTA comprises a sizable population of GABAergic inhibitory neurons ( 30\%) and excitatory glutamatergic neurons $(\sim 5 \%)$ (Nauta et al., 1978; Johnson and North, 1992). This DAergic group gives rise to the mesolimbic DA system projecting through the MFB primarily to the ventral striatum (NAc) (Dahlstroem and Fuxe, 1964). The A9 group is the most densely packed group of DAergic cells, which is located in the substantia nigra pars compacta $(\mathrm{SNc})$ and accounts for about $90 \%$ of the neuronal population in this relatively homogenous structure, in addition to a small population of GABAergic inhibitory neurons (10\%). The A9 group constitutes the nigrostriatal DAergic pathway which projects through the MFB to the dorsal striatum (dStr) composed of the caudate and putamen. Another small group of DAergic cells in rodents and primates is the A8 group, located in the midbrain reticular formation.

The DAergic signal arising from these midbrain structures enables basal ganglia (BG) control of motor planning and action selection (Wurtz and Hikosaka, 1986; Berns and Sejnowski, 1998; Gurney et al., 2001) by two parallel pathways diverging in the striatum and separating the BG loop into the direct, striatonigral pathway, and the indirect, striatopallidal pathway, via mediumsized spiny projection neurons (MSNs) expressing D1 receptors and D2 receptors, respectively (Alexander and Crutcher, 1990; Gerfen et al., 1990). The subthalamic nucleus which is a part of the indirect pathway also receives direct cortical input via the hyper-direct fast pathway that bypasses the striatum and is therefore independent of striatal DA input (Kita, 1992; Nambu et al., 2000, 2002). The balance between the direct and indirect pathways is thought to be essential for proper BG function (Albin et al., 1989; Wichmann and Delong, 1996; Delong and Wichmann, 2007). The MSNs, which are GABAergic neurons, make up the vast majority (90-95\%) of striatal neurons in rodents and primates (Kemp and Powell, 1971; Mensah and Deadwyler, 1974; Wilson and Groves, 1980; Graveland and Difiglia, 1985).
The MSNs relay information via the direct and indirect pathways to the two major output stations of the BG, the substantia nigra pars reticulata $(\mathrm{SNr})$ and the globus pallidus internal segment (or the entopeduncular nucleus in rodents) which are both primarily GABAergic (Van Der Kooy and Wise, 1980; Oertel and Mugnaini, 1984; Bolam et al., 1985, 1993; Parent and Hazrati, 1995).

\section{CONNECTIVITY WITHIN THE MESOSTRIATAL SYSTEMS}

The DA neurons in the SNc project predominantly to the striatum, which also receives a small percentage of DA inputs from the SNr and VTA (Van Der Kooy and Wise, 1980). Overall, at least $85 \%$ of the fibers reaching the striatum from the midbrain arise from the DA mesostriatal neurons. Of the $15 \%$ of the nonDA carrying fibers reaching the striatum, about $2 \%$ arrive from the VTA, 3-4\% from the SNc, and $8-9 \%$ arrive from the $\mathrm{SNr}$ (Van Der Kooy et al., 1981; Swanson, 1982; Fallon et al., 1983; Gerfen et al., 1987). In turn, neurons located in the striatal patches (Gerfen, 1984, 1985) project back to the DAergic neurons in the SNc (Gerfen et al., 1987). The two types of SNc neurons also project onto the NAc and comprise about $38 \%$ of its midbrain input (Swanson, 1982). The NAc projections back to the nigral complex are substantially larger than the nigrostriatal fibers it receives (Nauta et al., 1978).

All three types of VTA neurons project onto the NAc and comprise $40 \%$ of its midbrain input (Phillipson, 1979; Swanson, 1982). Of these NAc afferents, $85 \%$ are primarily DAergic and the remaining $15 \%$ arise from GABA or glutamate releasing neurons (Swanson, 1982; Gerfen et al., 1987; Gonzalez-Hernandez et al., 2004, p. 23; Stuber et al., 2012; Ishikawa et al., 2013). In turn, the NAc sends inhibitory projections back to VTA GABAergic neurons including those that innervated it, thus enabling reciprocal information transfer (Nauta et al., 1978; Phillipson, 1979; Kalivas et al., 1993). In addition, the VTA DAergic neurons are inhibited by GABAergic interneurons located in the VTA (Stuber et al., 2012; Van Zessen et al., 2012).

Approximately $1-3 \%$ of the DA fibers reaching the striatum come from the contralateral SNc, the VTA and the posterior lateral hypothalamic area (Veening et al., 1980; Gerfen et al., 1982; Swanson, 1982; Altar et al., 1983; Fallon et al., 1983; Consolazione et al., 1985; Lieu and Subramanian, 2012). Less than 10\% of the VTA efferents cross the midline to the contralateral side (Swanson, 1982) where they give rise to about $8 \%$ of the fibers reaching the NAc and about $1-3 \%$ of the fibers reaching the $\mathrm{dStr}$ (Carter and Fibiger, 1977; Altar et al., 1983; Douglas et al., 1987). This inter-hemispheric communication does not pass through the corpus callosum (Fass and Butcher, 1981) and instead decussates before the fibers reach the lateral hypothalamic area, close to the VTA (Altar et al., 1983; Douglas et al., 1987). It has been shown that VTA and SN neurons project either ipsilaterally or contralaterally but not bilaterally (Loughlin and Fallon, 1982).

\section{CONNECTIVITY BETWEEN THE MESOSTRIATAL SYSTEMS AND RELATED STRUCTURES}

The cortical targets of the SN include the PFC, the motor cortex and the EC (Loughlin and Fallon, 1984). All major regions of the cerebral cortex communicate with the striatum bilaterally, however, with ipsilateral predominance (Veening et al., 1980; Fisher 
et al., 1986; McGeorge and Faull, 1989; Brog et al., 1993; Totterdell and Meredith, 1997; Alloway et al., 2006; Lieu and Subramanian, 2012). Importantly, a single SN neuron sends collaterals to limbic, striatal, and cortical structures, unlike VTA neurons that can project solely to one terminal field (Loughlin and Fallon, 1984).

Projection neurons in the VTA arrive at the PFC and synapse on pyramidal neurons that project to the contralateral PFC (Carr and Sesack, 2000; Hnasko et al., 2012; Stuber et al., 2012) suggesting that the PFC is ideally suited to modulate inter-hemispheric information flow between itself and the BG. Additionally, the PFC sends excitatory glutamatergic projections onto VTA GABAergic neurons which innervate the NAc, and also onto VTA DAergic neurons which project back to the PFC (Carr and Sesack, 2000).

The VTA neurons also project to the EC of which $46 \%$ of the projections are DAergic. The EC in turn sends glutamatergic projections to the striatum, mainly to the NAc core (Krayniak et al., 1981; Finch et al., 1995; Moser et al., 2010). Similar to the VTANAc connectivity, the majority of the fibers (92\%) arrive at the ipsilateral EC whereas the remaining fibers reach the contralateral EC (Swanson, 1982). In addition to the bidirectional communication between the VTA and the NAc, and the VTA-EC-NAc circuit, these structures are also part of a complex loop engaging the hippocampus. Specifically, DAergic neurons in the VTA project to the hippocampus which through the subiculum, NAc and the ventral pallidum releases DA neurons in the VTA from tonic inhibitory ventral pallidum influence (Lisman and Grace, 2005). In addition, the glutamatergic neurons in the VTA project back to the ventral pallidum (Hnasko et al., 2012).

Observation of the mesostriatal and mesolimbic DA pathways reveals a symmetrical connectivity with a primary influence in the ipsilateral side and a minor influence in the contralateral side (illustrated in Figure 1). Symmetrical fiber connectivity entails that unilateral manipulations of the DA system will affect mainly the manipulated side and that the outcome of left vs. right manipulations will be symmetrical as long as physiological factors are not taken into account. Inter-hemispheric communication allowing bilateral influence of unilateral manipulation is supported primarily by the PFC without breaking the symmetry. It is noteworthy that information is lacking regarding fiber distribution differences in the left vs. right hemispheres. If fiber distribution differences exist, they may yield asymmetrical, bi-lateral response to a variety of unilateral manipulations.

\section{ENDOGENOUS ASYMMETRY IN THE DAergic SYSTEM}

Endogenous differences in the DA system of population of animals were observed in adulthood by many groups. These differences were expressed in DA level and metabolites, D1 and D2 receptor concentration, binding potential of the receptors and DA transporters measured in the neocortex, striatum and NAc. However, reports by different laboratories do not always concur in occurrence site, magnitude and the directionality of the observed imbalance (Glick et al., 1982; Schneider et al., 1982; Denenberg and Rosen, 1983; Drew et al., 1986; Fride and

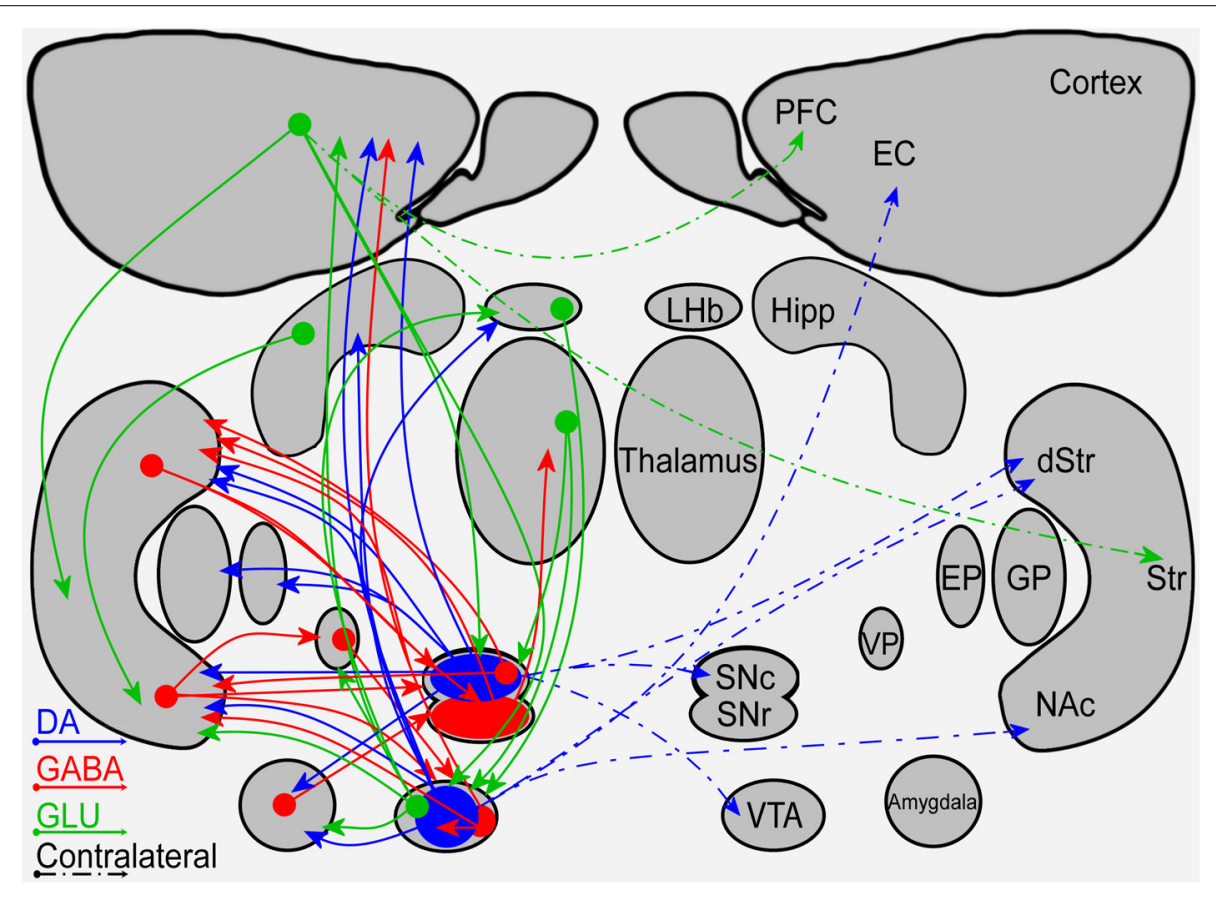

FIGURE 1 | A schematic diagram of the connectivity within and between the mesostriatal pathways and related structures. Shown are the ipsilateral (solid lines) and contralateral (dashed lines) projections of fibers containing DA (blue), GABA (red), or glutamate (green). Abbreviations: PFC, Prefrontal Cortex;
EC, Entorhinal cortex; Hipp, Hippocampus; LHb, Lateral Habenula; Str, Striatum; dStr, Dorsal Striatum; NAc, Nucleus Accumbens; GP, Globus pallidus; EP, Entopeduncular nucleus; VP, Ventral Pallidum; SNc, Substantia Nigra Pars Compacta; SNr, Substantia Nigra Pars Reticulata; VTA, Ventral Tegmental Area. 
Weinstock, 1987; Nowak, 1989; Rodriguez et al., 1994; Giardino, 1996; Becker, 1999; Thiel and Schwarting, 2001; Van Dyck et al., 2002; Silva et al., 2007; Vernaleken et al., 2007; Cannon et al., 2009; Martin-Soelch et al., 2011; Hsiao et al., 2013). Examination of the results and experimental conditions reveals, in addition to methodology of measurement, differences in animals' age, gender ratio, and in the species and strains of animals used. A clue for reconciling this discrepancy may be found in reports describing an inter-hemispheric regulatory/compensatory process which acts differentially in both hemispheres to restore DAergic balance. Such a process has been suggested to be active during development (Rodriguez et al., 1994; Giardino, 1996; Frohna et al., 1997; Vernaleken et al., 2007) and following tissue damage (Altar et al., 1983; Pritzel et al., 1983; Carlson et al., 1996; Roedter et al., 2001; Blesa et al., 2011). This regulatory/compensatory process which is time-dependent utilizes mechanisms of action such as controlling the ratio of D1/D2 receptors (Joyce, 1991a,b), changing the number of synaptic terminals (Jaeger et al., 1983; Lawler et al., 1995; Meshul et al., 1999; Gittis et al., 2011; Golden et al., 2013), and enhancing DA turnover and release from the available fibers (Ikegami et al., 2006). If the influence of this regulatory process on the expression of DA imbalance is experience dependent the discrepancy across laboratories could be reconciled because the variance in animals' experience is likely to be smaller within a laboratory than across laboratories. Hence, observation of hemispheric chemical imbalance may be obscured by the animal's unique experience and therefore studying DA imbalance in relation to animal behavior, preferably during a well-defined task, may minimize the influence of experience and could potentially reveal a robust effect that is consistent across laboratories.

\section{BEHAVIORAL CORRELATES OF ENDOGENOUS DA ASYMMETRY}

The degree of right hand preference in humans positively correlates with left putamen dominance, whereas right caudate dominance positively correlates with the level of performance during simultaneous bimanual movements in right-handed healthy subjects (De La Fuente-Fernandez et al., 2000). Rodents also display paw preference yet this preference is correlated with higher DA and DOPAC concentrations in the NAc ipsilateral to the preferred limb (Cabib et al., 1995; Budilin et al., 2008). Additionally, lateralization of DOPAC/DA ratios in favor of the right ventral striatum was positively related to right-side thigmotaxis (Thiel and Schwarting, 2001). Generally, however, spatial preference in rodents appears to be the manifestation of difference in activity occurring between the nigrostriatal systems. Specifically, rats forced to select a side (left or right) in a $\mathrm{T}$ maze displayed significantly higher DA content in the striatum contralateral to the preferred side than to the ipsilateral striatum (Zimmerberg et al., 1974). Similarly, the preferred direction of rotation was directly linked to the asymmetry in baseline DA (see Figure 2): the preferred direction of rotation was contralateral to the striatum with higher DA (Glick et al., 1988). Further support for this observation comes from intracranial self-stimulation experiments showing that the side having a lower threshold for stimulation was contralateral to the direction of spontaneous rotations (Glick et al., 1981). Opposite to DA levels, lower DOPAC values were

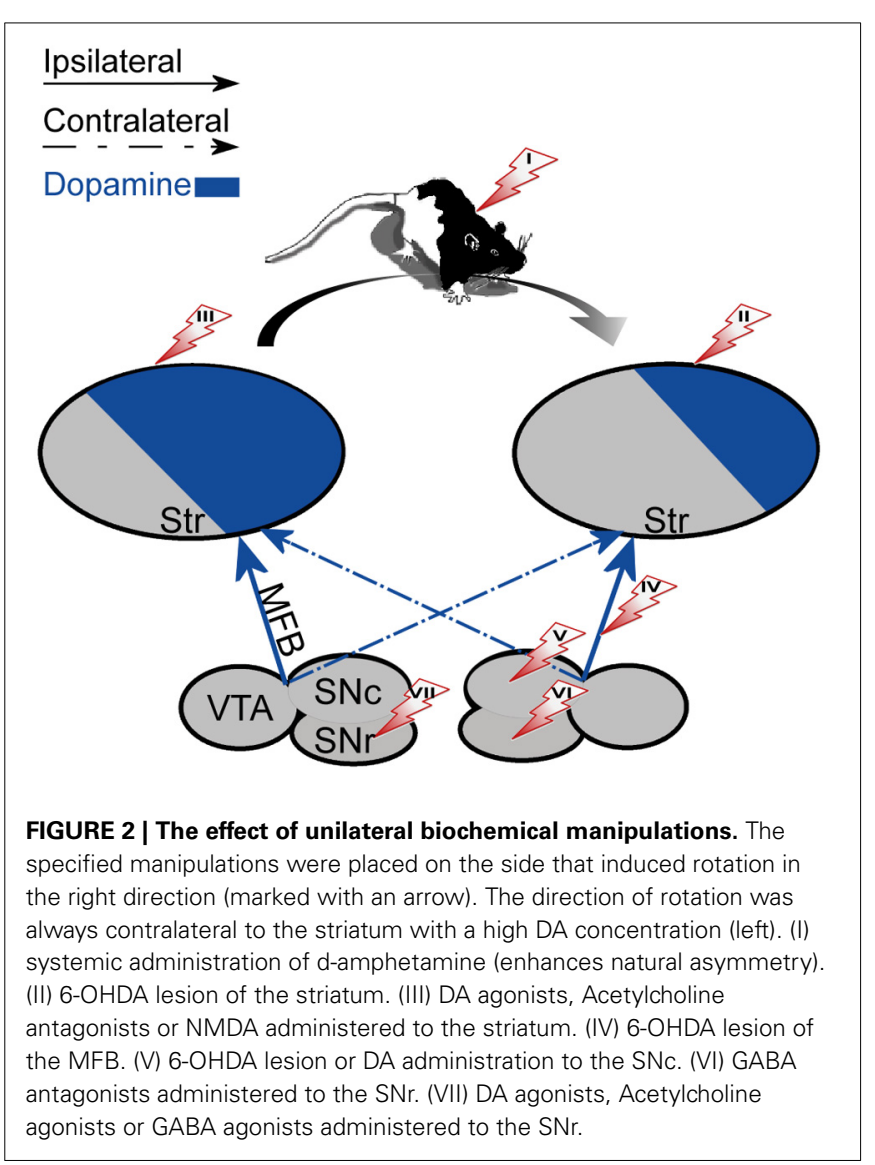

observed in the striatum contralateral to the preferred direction of rotation (Glick et al., 1977, 1988). However, haloperidol, which decreases the activation of DA receptors, inversed the relation between DOPAC concentration and direction of rotation without changing the animal's preferred direction (Jerussi and Taylor, 1982), suggesting that DOPAC concentration by itself may be a less reliable predictor of rotation direction. The preferred direction of rotation and paw preference in rodents are uncorrelated suggesting that they reflect two distinct processes (Nielsen et al., 1997) each correlated with DA asymmetry in a different striatal sub-region. This distinction in rodents contrasts with data showing a relation between human handedness and preferred direction of rotation; right-handers preferred left-sided turning and non-right-handers preferred right-sided turning (Mohr et al., 2003).

Other brain areas were also linked with spatial preference in rodents. For example, in the two-lever operant conditioning task rats showed a right lever bias that was correlated with enhanced activity in the left frontal cortex (Glick and Ross, 1981). Additionally, enhanced activity in the left PFC was observed during right rotation preference. These findings are consistent with reports of PFC-striatum interactions. Specifically, phasic activation of the PFC has been shown to increase DA release in the ipsilateral NAc (Taber and Fibiger, 1995) probably via glutamateinduced activation of DA neurons in the VTA (Karreman and Moghaddam, 1996). 
As opposed to the motor and sensory modalities displaying characteristic laterality, limbic entities such as stressors and natural rewards (food, liquid, or pleasure) lack laterality. Nonetheless, several studies suggest that endogenous DA asymmetry can be correlated with affective behaviors as well. For example, human baseline asymmetry in D2 receptor availability in the left relative to the right striatum was associated with greater positive incentive motivation (Tomer et al., 2008; Martin-Soelch et al., 2011). Moreover, human subjects with higher D2 binding in the left hemisphere were sensitive to learning from positive reinforcement whereas those with higher D2 binding in the right hemisphere were sensitive to learning from negative reinforcement (Tomer et al., 2014). Additionally, right-biased rats were significantly more active and had a stronger side preference than left-biased rats (Glick and Ross, 1981) which also may suggest attention/motivation influence.

\section{THE INFLUENCE OF BRAIN MANIPULATION ON ANIMAL BEHAVIOR}

In the previous section we reviewed evidence showing correlations between endogenous DA imbalance and natural behavior. In the following section we examine how systemic and unilateral artificial alteration of the inter-hemispheric DA imbalance influences animals' behavior.

\section{MANIPULATIONS IN THE NIGROSTRIATAL SYSTEM Systemic biochemical manipulations}

Systemic application of d-amphetamine, which enhances DA concentration at the DAergic terminals was found to enhance the rate of rotations in the preferred direction prior to the injection (Jerussi and Glick, 1976), as well as the inter-hemispheric difference in striatal DA content in a dose dependent manner (Glick et al., 1981). Moreover, d-amphetamine application further lowered the threshold for MFB activation and consequently further biased the side preference of self-stimulation (Glick et al., 1981). Apomorphine, which is a non-selective DA agonist, induced rotational behavior in rats similar to damphetamine. The induced rotation increased with apomorphine dosage until reaching a plateau (Jerussi and Glick, 1975). Conversely, apomorphine administration significantly decreased the number of times rats chose their preferred arm in a T-Maze but did not alter the side preference observed prior to drug application (Castellano et al., 1987) which may indicate drug spread into limbic regions. Inhibition of catecholamine synthesis by Alpha-methyl-para-tyrosine (AMPT) markedly reduced or completely abolished d-amphetamine induced rotation (Jerussi and Glick, 1976), but did not affect rotation elicited by apomorphine (Jerussi and Glick, 1975), suggesting that these two drugs operate differently. Haloperidol prevented the rotation elicited by both d-amphetamine and apomorphine (Jerussi and Glick, 1976), indicating its robust influence.

\section{Local biochemical manipulations}

A more selective way to induce DA imbalance in the nigrostriatal pathway is by unilaterally injecting DA agonists and antagonists into the dStr or the SN. Figure 2 summarizes the results obtained following unilateral manipulations. Local injection of DA into the
SNc induced weak ipsiversive or mixed ipsiversive and contraversive rotation probably due to DA autoreceptors which locally inhibit DA neurons (Jang et al., 2011). Injection of DA into the SNr only induced contraversive circling (Kelly et al., 1984). Local injection of apomorphine to the $\mathrm{SNr}$ or $\mathrm{SNc}$ had a mild influence on the tendency of the rats to rotate (Kelly et al., 1984), suggesting activation of other neuronal mechanisms that counteract the influence of apomorphine on DAergic neurons. Unilateral injections of apomorphine into the dStr induced contraversive turning as did injections of d-amphetamine, NMDA (Ossowska and Wolfarth, 1995), and atropine which is a muscarinic acetylcholine receptor antagonist (Jerussi and Glick, 1976).

GABA-related drugs and GABA antagonists applied intranigrally also facilitated rotational behavior; GABA, GABA $\mathrm{A}_{\mathrm{A}}$ agonist (e.g., muscimol) and GABA $_{B}$ agonists (e.g., $\gamma$-hydroxybutyric acid and baclofen) injected unilaterally into the $\mathrm{SNr}$ of rats elicited contraversive turning by disinhibiting the SNr influence on the striatum and enhancing DA activation ipsilaterally to the injection site, whereas unilateral injections of $\mathrm{GABA}_{\mathrm{A}}$ antagonist (e.g., bicuculline) produced ipsiversive turning by enhancing $\mathrm{SNr}$ inhibition of the striatum (Olpe et al., 1977; Scheel-Kruger et al., 1977).

Unilateral optical stimulation of MSNs in the direct or the indirect striatal pathways concurred with previously described manipulations which unilaterally enhanced or attenuated DA level; direct pathway activation led to contraversive rotation, whereas indirect pathway activation yielded ipsiversive rotation (Kravitz et al., 2010). Such a selective activation of the two pathways validates the influence of DA hemispheric imbalance on preferred rotation direction in the absence of a compensatory mechanism influence.

\section{Unilateral lesions using 6-hydroxydopamine}

6-hydroxydopamine (6-OHDA) is a neurotoxic compound that selectively destroys catecholamine neurons by penetrating their membrane via the DA or noradrenaline reuptake transporters (Simola et al., 2007). The 6-OHDA injection site determines the extent of damage caused by the neurotoxin and its specificity. Unilateral injection in the MFB has been shown to lesion both the uncrossed and crossed projections of the A9 and A10 cell groups converging on the ipsilateral dStr, and produces extensive catecholamine neuron destruction of about $97 \%$ of the cells primarily in the ipsilateral SNc and VTA. The contralateral SNc and VTA are less affected by the neurotoxin injection (Altar et al., 1983 ) because only a small percentage of their efferents ( $1 \%$ and $8 \%$ in the SNc and VTA, respectively) pass through the injection site (Iwamoto et al., 1976; Altar et al., 1983; Torres and Dunnett, 2012).

A more specific lesion can be produced by injecting the neurotoxin into the $\mathrm{SNc}$, which leads to the destruction of only the nigrostriatal (A9) pathway, and more focal damage can be created by lesioning sub-regions of the dStr complex, which induces cell death of 50-99\% of the SNc neurons depending on the affected dStr volume (reviewed in Deumens et al., 2002). These three procedures serve as classic animal models for Parkinson's disease (Ungerstedt and Arbuthnott, 1970; Simola et al., 2007). All of these lesions produce a biochemical imbalance in which lower 
DA levels are measured in the ipsilateral-to-lesion dStr than in the contralateral dStr. This biochemical imbalance is correlated with behavioral alterations such as the development of motor slowness and a turning preference bias toward the side of the lesion (Roedter et al., 2001; Simola et al., 2007). Specifically, 6-OHDA lesions of either the SNc, MFB, or the dStr induce ipsiversiveto-lesion rotation (Jerussi and Glick, 1976; Glick et al., 1977; Carman et al., 1991; Annett et al., 1992; Deumens et al., 2002). The lesion-induced turning behavior ceases within the first postoperative week (Pritzel et al., 1983) thus setting an upper bound on the time required for the compensatory processes to become evident.

It is interesting to note that unilateral optical activation of MSNs in the direct/indirect pathway induced contraversive/ipsiversive rotations similar to that induced by 6-OHDA lesions. This finding suggests that alterations in DA concentrations influence the balance in activation of the direct vs. indirect pathways; reduced DA concentration tips the scale toward activation of the striatopallidal pathway whereas enhanced DA concentration emphasizes the striatonigral pathway.

\section{Unilateral lesions and systemic biochemical manipulations}

Systemic administration of pharmacological agents influenced the direction of turning evoked by the 6-OHDA lesion by enhancing or reducing the lesion-induced biochemical imbalance. $\mathrm{d}$ amphetamine produced ipsilateral circling behavior whereas haloperidol and pimozide, which decrease the activation of DA receptors, produced contralateral circling behavior in rats with 6-OHDA lesion in the SNc (Iwamoto et al., 1976). Electrolytic lesions of the SNc induced a rotation preference similar to that induced by 6-OHDA (Arbuthnott and Crow, 1971; Iwamoto et al., 1976). Systemic administration of apomorphine generated a more complex outcome depending on the type and extent of the resulting tissue damage; apomorphine yielded contraversive circling following 6-OHDA lesions (Iwamoto et al., 1976; Glick et al., 1977; Meshul and Allen, 2000) and the number of rotations depended on the extent of tissue damage. By contrast, apomorphine led to ipsiversive circling following electrolytic lesion (Iwamoto et al., 1976).

Overall, artificial enhancement of striatal DA imbalance in rodents produces circling behavior in the direction toward the side with depleted DA concentration (see Figure 2). The outcome of this category of manipulations which ultimately influence striatal DA processing and transmission is consistent regardless of which component in the circuit has been manipulated and whether the manipulation enhanced or attenuated activity.

\section{MANIPULATIONS IN THE MESOLIMBIC SYSTEM}

Application of 6-OHDA to the mesolimbic system produced characteristic behavioral deficits different in nature from those produced by lesioning the nigrostriatal system. Unilateral injection of 6-OHDA to the right VTA or SN impaired acquisition of operant tasks (Hritcu et al., 2008). Bilateral small 6-OHDA lesions of the VTA produced a significant increase in spontaneous locomotor activity whereas large 6-OHDA lesions of the VTA or the NAc produced hypoactivity in the open field, a complete blockade of the locomotor stimulating effects of d-amphetamine, and a profound supersensitive response to apomorphine expressed as enhanced locomotion (Koob et al., 1981). Interestingly, a radiofrequency-VTA lesion caused a greater increase in spontaneous activity relative to the VTA 6-OHDA lesion, suggesting the presence of a powerful inhibitory influence of the mesolimbic DA system within the VTA (Koob et al., 1981).

\section{Manipulations of structures interacting with the mesolimbic system}

Experiments described thus far support the view that the relationship between the manipulation-induced DA imbalance and the animal's induced rotation direction is symmetric across hemispheres (see Figure 2). Experiments directly assessing the existence and function of DA imbalance in the mesolimbic pathway are lacking. However, some of the information can be deduced from experiments addressing the issue indirectly, for example, by applying pharmacological intervention in structures which interact with the mesolimbic system such as the PFC, EC, and hippocampus. Such experiments reveal that despite the apparent anatomical symmetry of the fibers unilateral manipulations influence the DA system asymmetrically. The results of these experiments are summarized in Table $\mathbf{1}$.

\section{The effect of PFC manipulations on the mesolimbic DA system}

The PFC represents information in the short term working memory (Kolb et al., 1994; Kesner et al., 1996; Goldman-Rakic, 2011) and is crucial for spatial and emotional response selection which are influenced by mesocortical DA (Thierry et al., 1976; Delatour and Gisquet-Verrier, 1999; Sullivan, 2004). As previously mentioned the interaction between mesostriatal DA and PFC is reciprocal (Carr and Sesack, 2000; Hnasko et al., 2012; Stuber et al., 2012). 6-OHDA lesions of the mesocortical DA innervating the right $\mathrm{mPFC}$ and anterior cingulate induced a significant bilateral reduction in DA content and an increase in DA turnover in the striatum (Sullivan and Szechtman, 1995). Similar lesions to the left mPFC and anterior cingulate did not affect striatal DA. Moreover, similar to unilateral lesion of the right PFC, bilateral lesions also reduced DA content and increased DA turnover but the response was limited to the right NAc (Sullivan and Szechtman, 1995). Evidence for the asymmetrical influence exerted by the PFC on the striatum also comes from studies performed on human subjects. For example, application of a continuous TMS theta burst stimulation (cTBS) to the left dorsolateral PFC of healthy young right-handed adults inhibited DA release bilaterally in the caudate and ipsilaterally in the putamen, whereas right dorsolateral PFC cTBS did not influence binding potential in the striatum (Ko et al., 2008).

A few studies correlated DA imbalance following chemical manipulations of the PFC with behavior. For example, correlations were observed between DA depletion induction in the right medial PFC ( $\mathrm{mPFC}$ ) and rats exhibiting the most severe stress-induced gastric pathology-ulcers (Sullivan and Szechtman, 1995). Additionally, unilateral injection of DA (D1/D2) antagonist into the mPFC significantly enhanced the restraint stress-induced increases in corticotrophin and corticosterone in non-handled rats (Sullivan and Dufresne, 2006). However, similar experiments in handled rats showed that only 
Table 1 | The reported directionality of DA imbalance in the mesolimbic system following biochemical and behavioral manipulations.

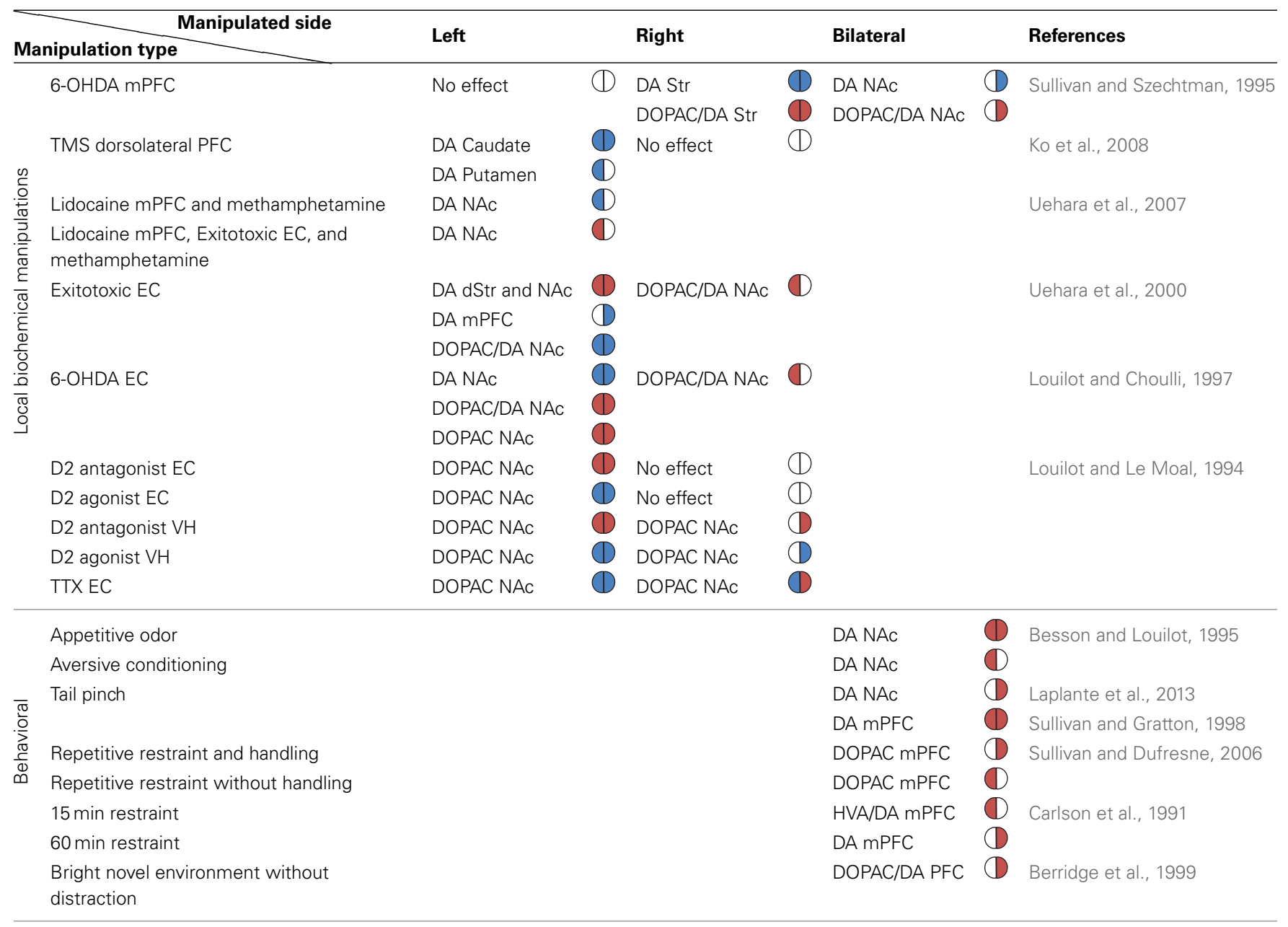

A circle denotes the spatial distribution of the manipulation outcome. Colored area indicates a significant increase (red) or decrease (blue) in DA or its metabolites in the corresponding hemisphere. Data were included from different species, ages, and measurement techniques.

right side DA receptor blockade induced elevation of peak stress hormone levels (Sullivan and Dufresne, 2006). These data provide supporting evidence for the asymmetrical relationship between DA imbalance in the mesolimbic system and the animals' affective behavior, and further emphasize that the animals' experience may hamper attempts to characterize this relationship.

\section{The effect of EC and hippocampus manipulations on the mesolimbic DA system}

The EC and the ventral hippocampus $(\mathrm{VH})$ receive DAergic projections from the VTA, and depending on event novelty (Lisman and Grace, 2005) act upon the VTA to regulate the DAergic transmission to the NAc (Louilot and Le Moal, 1994; Kurachi et al., 2000). Inter-hemispheric comparison of changes in DA and DOPAC concentration in the NAc and related regions following pharmacological intervention in the $\mathrm{EC}$ or $\mathrm{VH}$ revealed a timedependent process with complex lateralization. Excitotoxic lesion of the left EC decreased DOPAC levels in the NAc and the mPFC 2 weeks post lesion (Kurachi et al., 2000). Moreover, measurements performed in adolescence following excitotoxic lesion of the left EC in newborn rats showed bilateral enhancement of DA concentration in the NAc and dStr, and a unilateral decrease in the right $\mathrm{mPFC}$. The NAc also displayed a bilateral decrease in DOPAC/DA concentration ratio whereas the dStr did not. None of these alterations in the DA system was detected in the newborns (Uehara et al., 2000). When the left EC of adult rats was lesioned with 6-OHDA the outcome was reversed; DA tissue content decreased whereas DOPAC tissue content and the resultant DOPAC/DA ratio increased in the NAc (Louilot and Choulli, 1997). It remains to be seen whether the differences in outcome are due to the age at which the lesion was made or due to the lesion type. A similar lesion to the right EC caused elevation in DOPAC/DA ratio only in the left NAc (Louilot and Choulli, 1997). A more specific intervention by manipulation of both D1 and D2 receptors in the EC and VH significantly influenced DOPAC concentrations in the NAc such that the effect of the D2 manipulation was more pronounced than that of D1 (Louilot and Le Moal, 1994). Specifically, administration of a D2 receptor antagonist in the left EC increased DOPAC concentration in both NAc whereas administration of a D2 agonist caused the opposite effect (i.e., decreased DOPAC concentration in both NAc). Injection of a D2 antagonist or agonist into the right EC did not influence DOPAC levels in the NAc. Injections of a D2 antagonist and agonist into the $\mathrm{VH}$ evoked similar responses as left EC 
injections but the response was limited to the side ipsilateral to the injected hemisphere (Louilot and Le Moal, 1994). Moreover, injection of the neurotoxic compound Tetrodotoxin (TTX) into the left EC decreased DOPAC in both NAc whereas TTX in the right EC increased DA transmission in the ipsilateral NAc and decreased DOPAC in the contralateral NAc (Louilot and Le Moal, 1994). Unilateral TTX injections into the VH decreased DOPAC in the NAc of both hemispheres irrespective of injection side (Louilot and Le Moal, 1994). These side-dependent alterations in NAc DA release and its metabolites support the existence of an asymmetrical functional interdependence between midbrain DAergic pathways reaching the EC and the NAc (Louilot and Choulli, 1997).

Consistent with altered mesolimbic DAergic transmission, a left EC excitotoxic lesion in adult rats enhanced spontaneous and methamphetamine induced locomotor activity (Sumiyoshi et al., 2004; Kopniczky et al., 2006). Interestingly, the methamphetamine-induced normalized DA release in the ipsilateral NAc or dStr did not change in comparison to sham-operated animals possibly due to enhanced postsynaptic sensitivity rather than presynaptic alteration in DA levels (Uehara et al., 2000; Sumiyoshi et al., 2004). When the excitotoxic lesion to the left EC was combined with ipsilateral inactivation of the mPFC by lidocaine (a non-selective blocker of axonal fibers of passage as well as neurons) the methamphetamine-induced DA release in the ipsilateral NAc was substantially enhanced (Uehara et al., 2007). By contrast, ipsilateral inactivation of the MPFC by lidocaine alone reduced the methamphetamine-induced DA release in the NAc, which is consistent with previous data. Overall, inactivation of the mPFC together with structural abnormalities in the EC leads to deregulation of DAergic neurotransmission in limbic regions (Uehara et al., 2007).

The results described thus far strengthen assumptions concerning the lateralized involvement of the PFC, the EC, and the $\mathrm{VH}$ in the modulation and possibly regulation of mesostriatal DA asymmetry (Glick and Ross, 1981; Glick and Carlson, 1989; Fox and Reed, 2008). Overall, it seems that the nigrostriatal system displays symmetrical laterality (i.e., the outcome of different manipulations applied to one hemisphere is a mirror image of the outcome obtained when the manipulation is applied to other hemispheres), whereas the DA mesolimbic system and related structures display asymmetrical laterality (i.e., the outcome of different unilateral manipulations is not a mirror image of the same manipulation applied to the other hemisphere), The occurrence of an asymmetrical laterality supports the notion of specialized hemispheric function (Sullivan, 2004; Fox and Reed, 2008).

\section{THE INFLUENCE OF ANIMAL TRAINING ON DA IMBALANCE IN THE NIGROSTRIATAL SYSTEM}

Thus, far we have described how endogenous DA imbalance in the nigrostriatal system correlates with animal behavior and how accentuation of this biochemical imbalance can alter behavior. Below we address the opposite question of whether utilizing different behavioral tasks can induce or influence the basal DA imbalance.

Prior to training on an electrified T-maze (Zimmerberg et al., 1974) a relatively small percentage (about 54-59\%) of animals displayed side preference (Castellano et al., 1987). After training the vast majority $(85.71 \%)$ of the rats displayed a side preference with a strong bias toward the right arm (80\%—right arm preference; 20\%-left arm preference) (Castellano et al., 1987). Unilateral lesions using 6-OHDA ipsilaterally to the preferred side did not change preference parameters, whereas contralateral lesion massively and persistently decreased the choice of the side preferred preoperatively (Castellano et al., 1987). A similar outcome was observed when rats were trained to circle for a sucrose reward in a randomly assigned direction. Prior to training, caudate and NAc DA and DOPAC levels were the same in both hemispheres. By contrast, following training a significant increase occurred in both DA and DOPAC concentrations in the caudate and NAc contralateral to the turning direction whereas these concentrations did not change in the ipsilateral caudate compared to control animals (Yamamoto and Freed, 1982, 1984a). Amphetamine administration further enhanced turning in the trained direction regardless of the animals' previous circling preference. As in naive animals, amphetamine-induced circling led to increased DA concentrations in the caudate contralateral to the trained circling direction (Yamamoto and Freed, 1984b). These findings are congruent with the previously described relationship between DA imbalance and side preference.

Similar experiments (Szostak et al., 1986, 1988, 1989; Glick and Carlson, 1989) in which water-deprived animals were trained on circling behavior failed to replicate the results described by Yamamoto et al. (Yamamoto and Freed, 1982, 1984a,b). In particular, circling did not produce a biochemical imbalance in the nigrostriatal and the mesolimbic DA system; rats trained to circle using a continuous schedule of reinforcement did not exhibit any change in concentrations of striatal DA or DOPAC although alterations in DA and DA turnover were detected in the mPFC (Szostak et al., 1986; Glick and Carlson, 1989). Changing the reward schedule induced enhanced DAergic activity in both the NAc and the dStr (Szostak et al., 1986). A plausible explanation arises from a report which showed that different regions of the striatum exhibit different DA and DOPAC concentrations, thus suggesting striatal region specialization (Szostak et al., 1989). Importantly, the use of a water deprivation protocol without circling training was sufficient to induce a bilateral decrease in DOPAC/DA ratio in the NAc and mPFC (Glick and Carlson, 1989).

The following experiments further strengthen the relationship between DA imbalance and rotation direction. Unilateral 6-OHDA lesions of the MFB of rats trained to circle in their preferred direction for water reinforcement revealed a complex scenario that fits relatively well with the chemical imbalance described in control animals. Specifically, rats with a lesion contralateral to their trained direction stopped turning in that direction and often turned in the untrained direction. By contrast, rats lesioned ipsilaterally to the direction of reinforced circling exhibited only a $50 \%$ decrease in the rate of reinforced responding. These findings also highlight the effect of training on DA hemispheric imbalance. Following these procedures the experimental contingencies were reversed such that all rats had to turn in the untrained direction. After the reversal, the contralaterally lesioned group had to turn toward the lesion and 
consequently easily acquired the reversal, however, reinforced rates of responding did not reach preoperative rates possibly due to altered motivation (Mogenson et al., 1980; Smith et al., 2002; Wise, 2002; Solstad et al., 2008). Conversely, the ipsilaterally lesioned group had to turn away from the lesion and consequently was unable to acquire the reversal and continued to turn in the originally trained direction (Szostak et al., 1988). These findings are in line with the previously described rotation direction induced by 6-OHDA lesions. Moreover, these experiments suggest a causal relationship between DA imbalance and rotation direction because they imply that the direction of circling cannot be altered by training as long as the biochemical imbalance cannot be reversed.

Overall, by considering that alterations in DA/DOPAC concentrations resulting from training appear to be sensitive to variations in the training protocol such as reward schedule, severity and type of deprivation (food or water), type of reward delivered (sucrose, water, or food) and level of performance reached following training, the question whether DA imbalance may be effectively manipulated by training, which is a simple noninvasive procedure and as such may have a therapeutic capacity, remains controversial. These findings also raise the question whether the observed behavioral bias is a byproduct of the current DA imbalance or whether the regulatory mechanism promotes actions aimed to attenuate the inherent hemispheric laterality by overworking the less active regions.

\section{THE INFLUENCE OF ANIMAL TRAINING ON DA IMBALANCE IN THE MESOLIMBIC SYSTEM}

The question whether behavioral manipulations can induce or influence DA imbalance in the mesolimbic system has been addressed by utilizing different behavioral paradigms involving stress. Stress induction lacks laterality and therefore in all of the experiments emergent results reflect internal network properties. In this section we focus primarily on experiments showing DA measures in the NAc and PFC in attempt to identify whether laterality appears. A summary of the results is shown in Table 1.

DA responses to a naturally attractive olfactory stimulus were elevated in both NAc, most markedly in the right core. However, conditioned taste aversion following $\mathrm{LiCl}$ treatment resulted in elevation in DA levels in the left but not right NAc core which further expanded to the left shell upon a second presentation of the now aversive stimulus (Besson and Louilot, 1995). Different results were obtained when instead of presenting aversive stimulus physical stress was applied. The amplitude of DA release following tail pinch was higher in the right NAc compared to the left (Laplante et al., 2013) whereas in the mPFC DA release increased bilaterally (Sullivan and Gratton, 1998). Moreover, the duration of DA response in the left $\mathrm{MPFC}$ was significantly longer than that in the right mPFC (Sullivan and Gratton, 1998).

DA measures in the right $\mathrm{mPFC}$ correlated with reduced stress levels following 5 repetitions of restraint stress induction in both handled and non-handled animals (Sullivan and Dufresne, 2006). However, in handled rats DA turnover in the right mPFC was significantly higher than the left whereas in non-handled rats DA turnover in the left mPFC was significantly higher relative to the right mPFC (Sullivan and Dufresne, 2006). It should be noted however, that these results are incongruent with earlier findings regarding the cortical lateralization of emotional regulation which is facilitated by early postnatal handling stimulation, and fails to occur in the absence of postnatal handling (Denenberg, 1981; Sullivan and Dufresne, 2006). DA turnover in the right mPFC was higher than the left also in animals that received a foot shock without being able to terminate it (Carlson et al., 1993). When animals could control foot shock termination, DA turnover increased in the mPFC bilaterally (Carlson et al., 1993). Similarly, when rats and mice were exposed to a brightly lit novel environment (novelty stress) DA turnover in the right PFC was significantly higher than the left PFC in animals that weren't given the option of engaging in a non-escape behavior (e.g., chewing an inedible object), compared to those who did (Berridge et al., 1999). Thus, once animals are able to attenuate the physiological stress by controlling stressor termination or by engaging in a coping or displacement behavior the stress-induced DA response in the right PFC is attenuated (Berridge et al., 1999).

DA concentration measurements following different durations of restraint stress provide additional support for the correlation observed between stress level and DA imbalance in the mPFC. $\mathrm{DA}$ concentration increased in the right $\mathrm{mPFC}$ and reached significance relative to the left $\mathrm{mPFC}$ after the animals were kept restraint for an hour, and DA turnover was significantly higher in the left relative to the right $\mathrm{mPFC}$ following $15 \mathrm{~min}$ of restraint stress but not following prolonged restraint duration. These experiments suggest an alternative hypothesis in which a left to right shift in the mesocortical DA activation occurs with prolonged exposure to stress (Carlson et al., 1991).

The lack of agreement between these reports suggests that laterality in the mesolimbic DA system depends on factors such as the type of induced stress, stress duration and animal's previous experience (Denenberg, 1981; Fox and Reed, 2008). Therefore, these experiments do not allow addressing the question of whether causality exists between DA imbalance in the mesolimbic system and behavior; whether DA imbalance can reduce stress levels or alternatively that DA imbalance is determined by the animals' sensitivity to stress induction should be addressed by utilizing different experimental methods. In any case, despite the absence of a consistent link between behavioral manipulations lacking directionality and DA imbalance in the mesolimbic system these experiments support an asymmetrical processing characteristic of a specialized left vs. right network.

\section{DISCUSSION}

DA imbalance across brain hemispheres is inherent in newborns. With development, this imbalance decreases due to an interhemispheric time-dependent regulatory mechanism which differentially influences the DA system in each hemisphere (Rodriguez et al., 1994; Giardino, 1996; Frohna et al., 1997; Vernaleken et al., 2007). This mechanism also compensates for alterations in the endogenous DA imbalance following brain lesion and possibly neurodegenerative processes. The existence of such a mechanism raises the question whether there is a way to influence DA imbalance by utilizing specially designed behavioral manipulations that directly or indirectly activate the mechanism. Although 
controversial, studies in the nigrostriatal system suggest this possibility is feasible whereas in the mesolimbic system the feasibility of this approach remains to be explored. If successful, this approach can influence the development of novel non-invasive therapeutic means for the treatment of various disorders affected by alterations in DA imbalance.

The EC, the hippocampus, and PFC are part of a network which modulates NAc responses to DA arriving from the VTA. This network seems to display asymmetric left-right laterality rather than displaying the symmetric laterality observed in the nigrostriatal system. This difference in laterality is consistent with the roles played by each BG circuit: the sensorimotor and associative regions ( $\mathrm{dStr}$ ) display laterality which matches the laterality of their sensory inputs, whereas the limbic regions (NAc) which process abstract inputs supposedly lacking laterality are sensitive to the laterality of prefrontal and temporal lobe structures. Such laterality fits well with the concept of hemispheric specialization described in the PFC in relation to various behaviors (Clark et al., 2003; Sullivan, 2004; Goel et al., 2007; Fox and Reed, 2008; Lupinsky et al., 2010). Additional studies are required to determine whether the observed left-right laterality in the mesolimbic system has functional implications for information processing in subcortical structures (e.g., BG) or does it merely reflect the asymmetric functionality in structures such as the EC and the PFC.

The DA system plays a major role in the planning and execution of movements and in acquisition and expression of learned appetitive behaviors which allow the organism to adapt to its surrounding and thus essential for animals survival. To enable comprehensive understanding of the structure and function of this system, it is essential to plan and execute experiments which in addition to factors such as age, gender, and previous experience, take into account the existence of hemispheric specialization, the endogenous DA imbalance and its influence on behavior, and the way in which behavior can influence this imbalance.

\section{ACKNOWLEDGMENT}

This study was financed in part by a REALNET (FP7-ICT270434) grant from the European Commission.

\section{REFERENCES}

Albin, R. L., Young, A. B., and Penney, J. B. (1989). The functional anatomy of basal ganglia disorders. Trends Neurosci. 12, 366-375. doi: 10.1016/01662236(89)90074-X

Alexander, G. E., and Crutcher, M. D. (1990). Functional architecture of basal ganglia circuits: neural substrates of parallel processing. Trends Neurosci. 13, 266-271. doi: 10.1016/0166-2236(90)90107-L

Alloway, K. D., Lou, L., Nwabueze-Ogbo, F., and Chakrabarti, S. (2006). Topography of cortical projections to the dorsolateral neostriatum in rats: multiple overlapping sensorimotor pathways. J. Comp. Neurol. 499, 33-48. doi: $10.1002 /$ cne.21039

Altar, A., Neve, K. A., Loughlin, S. E., Marshall, J. F., and Fallon, J. H. (1983). The crossed mesostriatal projection: neurochemistry and developmental response to lesion. Brain Res. 279, 1-8. doi: 10.1016/0006-8993(83) 90157-9

Annett, L. E., Rogers, D. C., Hernandez, T. D., and Dunnett, S. B. (1992). Behavioural analysis of unilateral monoamine depletion in the marmoset. Brain 115(Pt 3), 825-856. doi: 10.1093/brain/115.3.825

Arbuthnott, G. W., and Crow, T. J. (1971). Relation of contraversive turning to unilateral release of dopamine from the nigrostriatal pathway in rats. Exp. Neurol. 30, 484-491. doi: 10.1016/0014-4886(71)90149-X
Becker, J. B. (1999). Gender differences in dopaminergic function in striatum and nucleus accumbens. Pharmacol. Biochem. Behav. 64, 803-812. doi: 10.1016/S0091-3057(99)00168-9

Berns, G. S., and Sejnowski, T. J. (1998). A computational model of how the basal ganglia produce sequences. J. Cogn. Neurosci. 10, 108-121. doi: 10.1162/08989 2998563815

Berridge, C. W., Mitton, E., Clark, W., and Roth, R. H. (1999). Engagement in a non-escape (displacement) behavior elicits a selective and lateralized suppression of frontal cortical dopaminergic utilization in stress. Synapse 32, 187-197. doi: 10.1002/(SICI)1098-2396(19990601)32:3\&lt;187::AID-SYN5\&gt; 3.0.CO;2-9

Besson, C., and Louilot, A. (1995). Asymmetrical involvement of mesolimbic dopaminergic neurons in affective perception. Neuroscience 68, 963-968. doi: 10.1016/0306-4522(95)00255-H

Blesa, J., Juri, C., Garcia-Cabezas, M. A., Adanez, R., Sanchez-Gonzalez, M. A., Cavada, C., et al. (2011). Inter-hemispheric asymmetry of nigrostriatal dopaminergic lesion: a possible compensatory mechanism in Parkinson's disease. Front. Syst. Neurosci. 5:92. doi: 10.3389/fnsys.2011.00092

Bolam, J. P., Powell, J. F., Wu, J. Y., and Smith, A. D. (1985). Glutamate decarboxylase-immunoreactive structures in the rat neostriatum: a correlated light and electron microscopic study including a combination of Golgi impregnation with immunocytochemistry. J. Comp. Neurol. 237, 1-20. doi: 10.1002/cne.902370102

Bolam, J. P., Smith, Y., Ingham, C. A., Von Krosigk, M., and Smith, A. D. (1993). Convergence of synaptic terminals from the striatum and the globus pallidus onto single neurones in the substantia nigra and the entopeduncular nucleus. Prog. Brain Res. 99, 73-88. doi: 10.1016/S0079-6123(08)61339-4

Bracha, H. S., Seitz, D. J., Otemaa, J., and Glick, S. D. (1987). Rotational movement (circling) in normal humans: sex difference and relationship to hand, foot and eye preference. Brain Res. 411, 231-235. doi: 10.1016/0006-8993(87) 91074-2

Brog, J. S., Salyapongse, A., Deutch, A. Y., and Zahm, D. S. (1993). The patterns of afferent innervation of the core and shell in the "accumbens" part of the rat ventral striatum: immunohistochemical detection of retrogradely transported fluoro-gold. J. Comp. Neurol. 338, 255-278. doi: 10.1002/cne.903380209

Budilin, S. Y., Midzyanovskaya, I. S., Shchegolevskii, N. V., Ioffe, M. E., and Bazyan, A. S. (2008). Asymmetry in dopamine levels in the nucleus accumbens and motor preference in rats. Neurosci. Behav. Physiol. 38, 991-994. doi: 10.1007/s11055-008-9082-6

Cabib, S., D’Amato, F. R., Neveu, P. J., Deleplanque, B., Le Moal, M., and Puglisi-Allegra, S. (1995). Paw preference and brain dopamine asymmetries. Neuroscience 64, 427-432. doi: 10.1016/0306-4522(94)00401-P

Cannon, D. M., Klaver, J. M., Peck, S. A., Rallis-Voak, D., Erickson, K., and Drevets, W. C. (2009). Dopamine type-1 receptor binding in major depressive disorder assessed using positron emission tomography and [11C]NNC-112. Neuropsychopharmacology 34, 1277-1287. doi: 10.1038/npp.2008.194

Carlson, J. N., Fitzgerald, L. W., Keller, R. W. Jr., and Glick, S. D. (1991). Side and region dependent changes in dopamine activation with various durations of restraint stress. Brain Res. 550, 313-318. doi: 10.1016/0006-8993(91)91333-V

Carlson, J. N., Fitzgerald, L. W., Keller, R. W. Jr., and Glick, S. D. (1993). Lateralized changes in prefrontal cortical dopamine activity induced by controllable and uncontrollable stress in the rat. Brain Res. 630, 178-187. doi: 10.1016/00068993(93)90655-7

Carlson, J. N., Visker, K. E., Keller, R. W. Jr., and Glick, S. D. (1996). Left and right 6-hydroxydopamine lesions of the medial prefrontal cortex differentially alter subcortical dopamine utilization and the behavioral response to stress. Brain Res. 711, 1-9. doi: 10.1016/0006-8993(95)01290-7

Carman, L. S., Gage, F. H., and Shults, C. W. (1991). Partial lesion of the substantia nigra: relation between extent of lesion and rotational behavior. Brain Res. 553, 275-283. doi: 10.1016/0006-8993(91)90835-J

Carr, D. B., and Sesack, S. R. (2000). Projections from the rat prefrontal cortex to the ventral tegmental area: target specificity in the synaptic associations with mesoaccumbens and mesocortical neurons. J. Neurosci. 20, 3864-3873.

Carter, D. A., and Fibiger, H. C. (1977). Ascending projections of presumed dopamine-containing neurons in the ventral tegmentum of the rat as demonstrated by horseradish peroxidase. Neuroscience 2, 569-576. doi: 10.1016/03064522(77)90052-5

Castellano, M. A., Diaz-Palarea, M. D., Rodriguez, M., and Barroso, J. (1987). Lateralization in male rats and dopaminergic system: evidence of right-side 
population bias. Physiol. Behav. 40, 607-612. doi: 10.1016/0031-9384(87) 90105-3

Clark, L., Manes, F., Antoun, N., Sahakian, B. J., and Robbins, T. W. (2003). The contributions of lesion laterality and lesion volume to decision-making impairment following frontal lobe damage. Neuropsychologia 41, 1474-1483. doi: 10.1016/S0028-3932(03)00081-2

Consolazione, A., Bentivoglio, M., Goldstein, M., and Toffano, G. (1985). Evidence for crossed catecholaminergic nigrostriatal projections by combining wheat germ agglutinin-horseradish peroxidase retrograde transport and tyrosine hydroxylase immunocytochemistry. Brain Res. 338, 140-143. doi: 10.1016/0006-8993(85)90256-2

Dahlstroem, A., and Fuxe, K. (1964). Evidence for the existence of monoaminecontaining neurons in the central nervous system. I. Demonstration of monoamines in the cell bodies of brain stem neurons. Acta Physiol. Scand. Suppl. Suppl. 232, 231-255.

Davidson, R. J., and Kenneth, H. (2004). The Asymmetrical Brain. Cambridge, MA: MIT Press.

De La Fuente-Fernandez, R., Kishore, A., Calne, D. B., Ruth, T. J., and Stoessl, A. J. (2000). Nigrostriatal dopamine system and motor lateralization. Behav. Brain Res. 112, 63-68. doi: 10.1016/S0166-4328(00)00165-0

Delatour, B., and Gisquet-Verrier, P. (1999). Lesions of the prelimbic-infralimbic cortices in rats do not disrupt response selection processes but induce delaydependent deficits: evidence for a role in working memory? Behav. Neurosci. 113, 941-955. doi: 10.1037/0735-7044.113.5.941

Delong, M. R., and Wichmann, T. (2007). Circuits and circuit disorders of the basal ganglia. Arch. Neurol. 64, 20-24. doi: 10.1001/archneur.64.1.20

Denenberg, V. H. (1981). Hemispheric laterality in animals and the effects of early experience. Behav. Brain Sci. 4, 1-49. doi: 10.1017/S0140525X00007330

Denenberg, V. H., and Rosen, G. D. (1983). Interhemispheric coupling coefficients: sex differences in brain neurochemistry. Am. J. Physiol. 245, R151-R153.

Deumens, R., Blokland, A., and Prickaerts, J. (2002). Modeling Parkinson's disease in rats: an evaluation of 6-OHDA lesions of the nigrostriatal pathway. Exp. Neurol. 175, 303-317. doi: 10.1006/exnr.2002.7891

Douglas, R., Kellaway, L., Mintz, M., and Van Wageningen, G. (1987). The crossed nigrostriatal projection decussates in the ventral tegmental decussation. Brain Res. 418, 111-121. doi: 10.1016/0006-8993(87)90967-X

Drew, K. L., Lyon, R. A., Titeler, M., and Glick, S. D. (1986). Asymmetry in D-2 binding in female rat striata. Brain Res. 363, 192-195. doi: 10.1016/00068993(86)90678-5

Fallon, J. H., Wang, C., Kim, Y., Canepa, N., Loughlin, S., and Seroogy, K. (1983). Dopamine- and cholecystokinin-containing neurons of the crossed mesostriatal projection. Neurosci. Lett. 40, 233-238. doi: 10.1016/0304-3940(83)90044-7

Fass, B., and Butcher, L. L. (1981). Evidence for a crossed nigrostriatal pathway in rats. Neurosci. Lett. 22, 109-113. doi: 10.1016/0304-3940(81)90072-0

Finch, D. M., Gigg, J., Tan, A. M., and Kosoyan, O. P. (1995). Neurophysiology and neuropharmacology of projections from entorhinal cortex to striatum in the rat. Brain Res. 670, 233-247. doi: 10.1016/0006-8993(94)01279-Q

Fisher, R. S., Boylan, M. K., Hull, C. D., Buchwald, N. A., and Levine, M. S. (1986). Branched projections of cat sensorimotor cortex: multiple retrograde labeling via commissural corticocortical, decussated corticostriatal and undecussated corticostriatal axons. Brain Res. 384, 395-400. doi: 10.1016/00068993(86)91180-7

Fox, N. A., and Reed, B. C. (2008). "Cortical Asymmetry-effects of early experience on the development of cerebral asymmetry and approach-withdrawal" in Handbook of Approach and Avoidance Motivation, ed A. J. Elliot (New York, NY: Psychology Press), 35-49.

Fride, E., and Weinstock, M. (1987). Increased interhemispheric coupling of the dopamine systems induced by prenatal stress. Brain Res. Bull. 18, 457-461. doi: 10.1016/0361-9230(87)90020-7

Frohna, P. A., Neal-Beliveau, B. S., and Joyce, J. N. (1997). Delayed plasticity of the mesolimbic dopamine system following neonatal 6-OHDA lesions. Synapse 25, 293-305. doi: 10.1002/(SICI)1098-2396(199703)25:3<293::AIDSYN9>3.0.CO;2-6

Gazzaniga, M. S. (1995). Principles of human brain organization derived from split-brain studies. Neuron 14, 217-228. doi: 10.1016/0896-6273(95)90280-5

Gerfen, C. R. (1984). The neostriatal mosaic: compartmentalization of corticostriatal input and striatonigral output systems. Nature 311, 461-464. doi: $10.1038 / 311461 \mathrm{a} 0$
Gerfen, C. R. (1985). The neostriatal mosaic. I. Compartmental organization of projections from the striatum to the substantia nigra in the rat. J. Comp. Neurol. 236, 454-476. doi: 10.1002/cne.902360404

Gerfen, C. R., Engber, T. M., Mahan, L. C., Susel, Z., Chase, T. N., Monsma, F. J., et al. (1990). D1 and D2 dopamine receptor-regulated gene expression of striatonigral and striatopallidal neurons. Science 250, 1429-1432. doi: $10.1126 /$ science. 2147780

Gerfen, C. R., Herkenham, M., and Thibault, J. (1987). The neostriatal mosaic: II. Patch- and matrix-directed mesostriatal dopaminergic and non-dopaminergic systems. J. Neurosci. 7, 3915-3934.

Gerfen, C. R., Staines, W. A., Arbuthnott, G. W., and Fibiger, H. C. (1982). Crossed connections of the substantia nigra in the rat. J. Comp. Neurol. 207, 283-303. doi: 10.1002/cne.902070308

Giardino, L. (1996). Right-left asymmetry of D1- and D2-receptor density is lost in the basal ganglia of old rats. Brain Res. 720, 235-238. doi: 10.1016/00068993(96)00144-8

Gittis, A. H., Hang, G. B., Ladow, E. S., Shoenfeld, L. R., Atallah, B. V., Finkbeiner, S., et al. (2011). Rapid target-specific remodeling of fastspiking inhibitory circuits after loss of dopamine. Neuron 71, 858-868. doi: 10.1016/j.neuron.2011.06.035

Glick, S. D., and Carlson, J. N. (1989). Regional changes in brain dopamine and serotonin metabolism induced by conditioned circling in rats: effects of water deprivation, learning and individual differences in asymmetry. Brain Res. 504, 231-237. doi: 10.1016/0006-8993(89)91362-0

Glick, S. D., Carlson, J. N., Baird, J. L., Maisonneuve, I. M., and Bullock, A. E. (1988). Basal and amphetamine-induced asymmetries in striatal dopamine release and metabolism: bilateral in vivo microdialysis in normal rats. Brain Res. 473, 161-164. doi: 10.1016/0006-8993(88)90329-0

Glick, S. D., Jerussi, T. P., and Zimmerberg, B. (1977). "Behavioral and neuropharmacological correlates of nigrostriatal asymmetry in rats," in Lateralization in the Nervous System, ed S. Harnad (Oxford: Elsevier Science), 213-249. doi: 10.1016/B978-0-12-325750-5.50020-8

Glick, S. D., and Ross, D. A. (1981). Right-sided population bias and lateralization of activity in normal rats. Brain Res. 205, 222-225. doi: 10.1016/00068993(81)90737-X

Glick, S. D., Ross, D. A., and Hough, L. B. (1982). Lateral asymmetry of neurotransmitters in human brain. Brain Res. 234, 53-63. doi: 10.1016/00068993(82)90472-3

Glick, S. D., Weaver, L. M., and Meibach, R. C. (1981). Amphetamine enhancement of reward asymmetry. Psychopharmacology (Berl.) 73, 323-327. doi: 10.1007/BF00426459

Goel, V., Tierney, M., Sheesley, L., Bartolo, A., Vartanian, O., and Grafman, J. (2007). Hemispheric specialization in human prefrontal cortex for resolving certain and uncertain inferences. Cereb. Cortex 17, 2245-2250. doi: 10.1093/cercor/bhl132

Golden, J. P., Demaro, J. A. 3rd., Knoten, A., Hoshi, M., Pehek, E., Johnson, E. M., et al. (2013). Dopamine-dependent compensation maintains motor behavior in mice with developmental ablation of dopaminergic neurons. J. Neurosci. 33, 17095-17107. doi: 10.1523/JNEUROSCI.0890-13.2013

Goldman-Rakic, P. S. (2011). Circuitry of primate prefrontal cortex and regulation of behavior by representational memory. Compr. Physiol. 373-417. doi: 10.1002/cphy.cp010509

Gonzalez-Hernandez, T., Barroso-Chinea, P., and Rodriguez, M. (2004). Response of the GABAergic and dopaminergic mesostriatal projections to the lesion of the contralateral dopaminergic mesostriatal pathway in the rat. Mov. Disord. 19, 1029-1042. doi: 10.1002/mds.20206

Gotts, S. J., Jo, H. J., Wallace, G. L., Saad, Z. S., Cox, R. W., and Martin, A. (2013). Two distinct forms of functional lateralization in the human brain. Proc. Natl. Acad. Sci. U.S.A. 110, E3435-E3444. doi: 10.1073/pnas.1302581110

Graveland, G. A., and Difiglia, M. (1985). The frequency and distribution of medium-sized neurons with indented nuclei in the primate and rodent neostriatum. Brain Res. 327, 307-311. doi: 10.1016/0006-8993(85)91524-0

Gruzelier, J. H. (1999). Functional neuropsychophysiological asymmetry in schizophrenia: a review and reorientation. Schizophr. Bull. 25, 91-120. doi: 10.1093/oxfordjournals.schbul.a033370

Gurney, K., Prescott, T. J., and Redgrave, P. (2001). A computational model of action selection in the basal ganglia. I. A new functional anatomy. Biol. Cybern. 84, 401-410. doi: 10.1007/PL00007984 
Hietala, J., Syvalahti, E., Vilkman, H., Vuorio, K., Rakkolainen, V., Bergman, J., et al. (1999). Depressive symptoms and presynaptic dopamine function in neuroleptic-naive schizophrenia. Schizophr. Res. 35, 41-50. doi: 10.1016/S09209964(98)00113-3

Hnasko, T. S., Hjelmstad, G. O., Fields, H. L., and Edwards, R. H. (2012). Ventral tegmental area glutamate neurons: electrophysiological properties and projections. J. Neurosci. 32, 15076-15085. doi: 10.1523/JNEUROSCI.3128-12.2012

Hritcu, L., Ciobica, A., and Artenie, V. (2008). Effects of right-unilateral 6-hydroxydopamine infusion-induced memory impairment and oxidative stress: relevance for Parkinson's disease. Cent. Eur. J. Biol. 3, 250-257. doi: 10.2478/s11535-008-0023-8

Hsiao, M. C., Lin, K. J., Liu, C. Y., and Schatz, D. B. (2013). The interaction between dopamine transporter function, gender differences, and possible laterality in depression. Psychiatry Res. 211, 72-77. doi: 10.1016/j.pscychresns.2012.06.004

Hsiao, M. C., Lin, K. J., Liu, C. Y., Tzen, K. Y., and Yen, T. C. (2003). Dopamine transporter change in drug-naive schizophrenia: an imaging study with $99 \mathrm{mTc}$ TRODAT-1. Schizophr. Res. 65, 39-46. doi: 10.1016/S0920-9964(03)00006-9

Ikegami, M., Ichitani, Y., Takahashi, T., and Iwasaki, T. (2006). Compensatory increase in extracellular dopamine in the nucleus accumbens of adult rats with neonatal 6-hydroxydopamine treatment. Nihon Shinkei Seishin Yakurigaku Zasshi 26, 111-117.

Ishikawa, M., Otaka, M., Huang, Y. H., Neumann, P. A., Winters, B. D., Grace, A. A., et al. (2013). Dopamine triggers heterosynaptic plasticity. J. Neurosci. 33, 6759-6765. doi: 10.1523/JNEUROSCI.4694-12.2013

Iwamoto, E. T., Loh, H. H., and Way, E. L. (1976). Circling behavior in rats with 6hydroxydopamine or electrolytic nigral lesions. Eur. J. Pharmacol. 37, 339-356. doi: 10.1016/0014-2999(76)90042-X

Jaeger, C. B., Joh, T. H., and Reis, D. J. (1983). The effect of forebrain lesions in the neonatal rat: survival of midbrain dopaminergic neurons and the crossed nigrostriatal projection. J. Comp. Neurol. 218, 74-90. doi: $10.1002 /$ cne. 902180105

Jang, J. Y., Jang, M., Kim, S. H., Um, K. B., Kang, Y. K., Kim, H. J., et al. (2011). Regulation of dopaminergic neuron firing by heterogeneous dopamine autoreceptors in the substantia nigra pars compacta. J. Neurochem. 116, 966-974. doi: 10.1111/j.1471-4159.2010.07107.x

Jerussi, T. P., and Glick, S. D. (1975). Apomorphine-induced rotation in normal rats and interaction with unilateral caudate lesions. Psychopharmacologia 40, 329-334. doi: 10.1007/BF00421471

Jerussi, T. P., and Glick, S. D. (1976). Drug-induced rotation in rats without lesions: behavioral and neurochemical indices of a normal asymmetry in nigro-striatal function. Psychopharmacology (Berl.) 47, 249-260. doi: 10.1007/BF00427609

Jerussi, T. P., and Taylor, C. A. (1982). Bilateral asymmetry in striatal dopamine metabolism: implications for pharmacotherapy of schizophrenia. Brain Res. 246, 71-75. doi: 10.1016/0006-8993(82)90143-3

Johnson, S. W., and North, R. A. (1992). Two types of neurone in the rat ventral tegmental area and their synaptic inputs. J. Physiol. 450, 455-468.

Joyce, J. N. (1991a). Differential response of striatal dopamine and muscarinic cholinergic receptor subtypes to the loss of dopamine. I. Effects of intranigral or intracerebroventricular 6-hydroxydopamine lesions of the mesostriatal dopamine system. Exp. Neurol. 113, 261-276. doi: 10.1016/00144886(91)90016-6

Joyce, J. N. (1991b). Differential response of striatal dopamine and muscarinic cholinergic receptor subtypes to the loss of dopamine. II. Effects of 6hydroxydopamine or colchicine microinjections into the VTA or reserpine treatment. Exp. Neurol. 113, 277-290. doi: 10.1016/0014-4886(91)90017-7

Kalivas, P. W., Churchill, L., and Klitenick, M. A. (1993). GABA and enkephalin projection from the nucleus accumbens and ventral pallidum to the ventral tegmental area. Neuroscience 57, 1047-1060. doi: 10.1016/0306-4522(93) 90048-K

Karreman, M., and Moghaddam, B. (1996). The prefrontal cortex regulates the basal release of dopamine in the limbic striatum: an effect mediated by ventral tegmental area. J. Neurochem. 66, 589-598. doi: 10.1046/j.14714159.1996.66020589.x

Kelly, E., Jenner, P., and Marsden, C. D. (1984). Behavioural effects mediated by unilateral nigral dopamine receptor stimulation in the rat. Exp. Brain Res. 55, 243-252. doi: 10.1007/BF00237275

Kemp, J. M., and Powell, T. P. (1971). The structure of the caudate nucleus of the cat: light and electron microscopy. Philos. Trans. R. Soc. Lond. B Biol. Sci. 262, 383-401. doi: 10.1098/rstb.1971.0102
Kesner, R. P., Hunt, M. E., Williams, J. M., and Long, J. M. (1996). Prefrontal cortex and working memory for spatial response, spatial location, and visual object information in the rat. Cereb. Cortex 6, 311-318. doi: 10.1093/cercor/ 6.2.311

Kimura, D., and Archibald, Y. (1974). Motor functions of the left hemisphere. Brain 97, 337-350. doi: 10.1093/brain/97.1.337

Kita, H. (1992). Responses of globus pallidus neurons to cortical stimulation: intracellular study in the rat. Brain Res. 589, 84-90. doi: 10.1016/00068993(92)91164-A

Ko, J. H., Monchi, O., Ptito, A., Bloomfield, P., Houle, S., and Strafella, A. P. (2008). Theta burst stimulation-induced inhibition of dorsolateral prefrontal cortex reveals hemispheric asymmetry in striatal dopamine release during a set-shifting task: a TMS-[(11)C]raclopride PET study. Eur. J. Neurosci. 28, 2147-2155. doi: 10.1111/j.1460-9568.2008.06501.x

Kolb, B., Buhrmann, K., McDonald, R., and Sutherland, R. J. (1994). Dissociation of the medial prefrontal, posterior parietal, and posterior temporal cortex for spatial navigation and recognition memory in the rat. Cereb. Cortex 4, 664-680. doi: 10.1093/cercor/4.6.664

Koob, G. F., Stinus, L., and Le Moal, M. (1981). Hyperactivity and hypoactivity produced by lesions to the mesolimbic dopamine system. Behav. Brain Res. 3, 341-359. doi: 10.1016/0166-4328(81)90004-8

Kopniczky, Z., Dochnal, R., Macsai, M., Pal, A., Kiss, G., Mihaly, A., et al. (2006). Alterations of behavior and spatial learning after unilateral entorhinal ablation of rats. Life Sci. 78, 2683-2688. doi: 10.1016/j.lfs.2005.10.014

Kravitz, A. V., Freeze, B. S., Parker, P. R., Kay, K., Thwin, M. T., Deisseroth, K., et al. (2010). Regulation of parkinsonian motor behaviours by optogenetic control of basal ganglia circuitry. Nature 466, 622-626. doi: 10.1038/nature09159

Krayniak, P. F., Meibach, R. C., and Siegel, A. (1981). A projection from the entorhinal cortex to the nucleus accumbens in the rat. Brain Res. 209, 427-431. doi: 10.1016/0006-8993(81)90165-7

Kurachi, M., Sumiyoshi, T., Shibata, R., Sun, Y. J., Uehara, T., Tanii, Y., et al. (2000). Changes in limbic dopamine metabolism following quinolinic acid lesions of the left entorhinal cortex in rats. Psychiatry Clin. Neurosci. 54, 83-89. doi: 10.1046/j.1440-1819.2000.00641.x

Laplante, F., Dufresne, M. M., Ouboudinar, J., Ochoa-Sanchez, R., and Sullivan, R. M. (2013). Reduction in cholinergic interneuron density in the nucleus accumbens attenuates local extracellular dopamine release in response to stress or amphetamine. Synapse 67, 21-29. doi: 10.1002/syn.21612

Lawler, C. P., Gilmore, J. H., Watts, V. J., Walker, Q. D., Southerland, S. B., Cook, L. L., et al. (1995). Interhemispheric modulation of dopamine receptor interactions in unilateral 6-OHDA rodent model. Synapse 21, 299-311. doi: 10.1002/syn.890210404

Lieu, C. A., and Subramanian, T. (2012). The interhemispheric connections of the striatum: implications for Parkinson's disease and drug-induced dyskinesias. Brain Res. Bull. 87, 1-9. doi: 10.1016/j.brainresbull.2011.09.013

Lisman, J. E., and Grace, A. A. (2005). The hippocampal-VTA loop: controlling the entry of information into long-term memory. Neuron 46, 703-713. doi: 10.1016/j.neuron.2005.05.002

Loughlin, S. E., and Fallon, J. H. (1982). Mesostriatal projections from ventral tegmentum and dorsal raphe: cells project ipsilaterally or contralaterally but not bilaterally. Neurosci. Lett. 32, 11-16. doi: 10.1016/0304-3940(82) 90221-X

Loughlin, S. E., and Fallon, J. H. (1984). Substantia nigra and ventral tegmental area projections to cortex: topography and collateralization. Neuroscience 11, 425-435. doi: 10.1016/0306-4522(84)90034-4

Louilot, A., and Choulli, M. K. (1997). Asymmetrical increases in dopamine turnover in the nucleus accumbens and lack of changes in locomotor responses following unilateral dopaminergic depletions in the entorhinal cortex. Brain Res. 778, 150-157. doi: 10.1016/S0006-8993(97)01050-0

Louilot, A., and Le Moal, M. (1994). Lateralized interdependence between limbicotemporal and ventrostriatal dopaminergic transmission. Neuroscience 59, 495-500. doi: 10.1016/0306-4522(94)90171-6

Lupinsky, D., Moquin, L., and Gratton, A. (2010). Interhemispheric regulation of the medial prefrontal cortical glutamate stress response in rats. J. Neurosci. 30, 7624-7633. doi: 10.1523/JNEUROSCI.1187-10.2010

Martin-Soelch, C., Szczepanik, J., Nugent, A., Barhaghi, K., Rallis, D., Herscovitch, P., et al. (2011). Lateralization and gender differences in the dopaminergic response to unpredictable reward in the human ventral striatum. Eur. J. Neurosci. 33, 1706-1715. doi: 10.1111/j.1460-9568.2011.07642.x 
McGeorge, A. J., and Faull, R. L. (1989). The organization of the projection from the cerebral cortex to the striatum in the rat. Neuroscience 29, 503-537. doi: 10.1016/0306-4522(89)90128-0

Mensah, P., and Deadwyler, S. (1974). The caudate nucleus of the rat: cell types and the demonstration of a commissural system. J. Anat. 117, 281-293.

Meshul, C. K., and Allen, C. (2000). Haloperidol reverses the changes in striatal glutamatergic immunolabeling following a 6-OHDA lesion. Synapse 36, 129-142. doi: 10.1002/(SICI) 1098-2396(200005)36:2<129::AID-SYN6>3.0.CO;2-4

Meshul, C. K., Emre, N., Nakamura, C. M., Allen, C., Donohue, M. K., and Buckman, J. F. (1999). Time-dependent changes in striatal glutamate synapses following a 6-hydroxydopamine lesion. Neuroscience 88, 1-16. doi: 10.1016/ S0306-4522(98)00189-4

Mogenson, G. J., Jones, D. L., and Yim, C. Y. (1980). From motivation to action: functional interface between the limbic system and the motor system. Prog. Neurobiol. 14, 69-97. doi: 10.1016/0301-0082(80)90018-0

Mohr, C., and Bracha, H. S. (2004). Compound measure of hand-foot-eye preference masked opposite turning behavior in healthy right-handers and nonright-handers: technical comment on Mohr et al. (2003). Behav. Neurosci. 118, 1145-1146. doi: 10.1037/0735-7044.118.5.1145

Mohr, C., Landis, T., Bracha, H. S., and Brugger, P. (2003). Opposite turning behavior in right-handers and non-right-handers suggests a link between handedness and cerebral dopamine asymmetries. Behav. Neurosci. 117, 1448-1452. doi: 10.1037/0735-7044.117.6.1448

Moser, E. I., Witter, M. P., and Moser, M. B. (2010). "Entorhinal cortex" in Handbook of Brain Microcircuits, eds S. M. Gordon and S. Grillner (New York, NY: Oxford University Press), 175-192.

Nambu, A., Tokuno, H., Hamada, I., Kita, H., Imanishi, M., Akazawa, T., et al. (2000). Excitatory cortical inputs to pallidal neurons via the subthalamic nucleus in the monkey. J. Neurophysiol. 84, 289-300.

Nambu, A., Tokuno, H., and Takada, M. (2002). Functional significance of the cortico-subthalamo-pallidal 'hyperdirect' pathway. Neurosci. Res. 43, 111-117. doi: 10.1016/S0168-0102(02)00027-5

Nauta, W. J., Smith, G. P., Faull, R. L., and Domesick, V. B. (1978). Efferent connections and nigral afferents of the nucleus accumbens septi in the rat. Neuroscience 3, 385-401. doi: 10.1016/0306-4522(78)90041-6

Nielsen, D. M., Visker, K. E., Cunningham, M. J., Keller, R. W. Jr., Glick, S. D., and Carlson, J. N. (1997). Paw preference, rotation, and dopamine function in Collins HI and LO mouse strains. Physiol. Behav. 61, 525-535. doi: 10.1016/S0031-9384(96)00496-9

Nowak, G. (1989). Lateralization of neocortical dopamine receptors and dopamine level in normal Wistar rats. Pol. J. Pharmacol. Pharm. 41, 133-137.

Oertel, W. H., and Mugnaini, E. (1984). Immunocytochemical studies of GABAergic neurons in rat basal ganglia and their relations to other neuronal systems. Neurosci. Lett. 47, 233-238. doi: 10.1016/0304-3940(84)90519-6

Olpe, H. R., Schellenberg, H., and Koella, W. P. (1977). Rotational behavior induced in rats by intranigral application of GABA-related drugs and GABA antagonists. Eur. J. Pharmacol. 45, 291-294. doi: 10.1016/0014-2999(77)90012-7

Ossowska, K., and Wolfarth, S. (1995). Stimulation of glutamate receptors in the intermediate/caudal striatum induces contralateral turning. Eur. J. Pharmacol. 273, 89-97. doi: 10.1016/0014-2999(94)00671-S

Parent, A., and Hazrati, L. N. (1995). Functional anatomy of the basal ganglia. I. The cortico-basal ganglia-thalamo-cortical loop. Brain Res. Brain Res. Rev. 20, 91-127. doi: 10.1016/0165-0173(94)00007-C

Peterson, B. S., Riddle, M. A., Cohen, D. J., Katz, L. D., Smith, J. C., and Leckman, J. F. (1993). Human basal ganglia volume asymmetries on magnetic resonance images. Magn. Reson. Imaging 11, 493-498. doi: 10.1016/0730-725X(93) 90468-S

Phillipson, O. T. (1979). Afferent projections to the ventral tegmental area of Tsai and interfascicular nucleus: a horseradish peroxidase study in the rat. J. Comp. Neurol. 187, 117-143. doi: 10.1002/cne.901870108

Pritzel, M., Huston, J. P., and Sarter, M. (1983). Behavioral and neuronal reorganization after unilateral substantia nigra lesions: evidence for increased interhemispheric nigrostriatal projections. Neuroscience 9, 879-888. doi: 10.1016/03064522(83)90276-2

Rodriguez, M., Martin, L., and Santana, C. (1994). Ontogenic development of brain asymmetry in dopaminergic neurons. Brain Res. Bull. 33, 163-171. doi: 10.1016/0361-9230(94)90246-1

Roedter, A., Winkler, C., Samii, M., Walter, G. F., Brandis, A., and Nikkhah, G. (2001). Comparison of unilateral and bilateral intrastriatal 6-hydroxydopamine-induced axon terminal lesions: evidence for interhemispheric functional coupling of the two nigrostriatal pathways. J. Comp. Neurol. 432, 217-229. doi: 10.1002/cne.1098

Scheel-Kruger, J., Arnt, J., and Magelund, G. (1977). Behavioural stimulation induced by muscimol and other GABA agonists injected into the substantia nigra. Neurosci. Lett. 4, 351-356. doi: 10.1016/0304-3940(77)90183-5

Schneider, L. H., Murphy, R. B., and Coons, E. E. (1982). Lateralization of striatal dopamine (D2) receptors in normal rats. Neurosci. Lett. 33, 281-284. doi: 10.1016/0304-3940(82)90385-8

Seibyl, J. P., Marek, K. L., Quinlan, D., Sheff, K., Zoghbi, S., Zea-Ponce, Y., et al. (1995). Decreased single-photon emission computed tomographic [123I]betaCIT striatal uptake correlates with symptom severity in Parkinson's disease. Ann. Neurol. 38, 589-598. doi: 10.1002/ana.410380407

Silva, M. A., Topic, B., Lamounier-Zepter, V., Huston, J. P., Tomaz, C., and Barros, M. (2007). Evidence for hemispheric specialization in the marmoset (Callithrix penicillata) based on lateralization of behavioral/neurochemical correlations. Brain Res. Bull. 74, 416-428. doi: 10.1016/j.brainresbull.2007.07.012

Simola, N., Morelli, M., and Carta, A. R. (2007). The 6-hydroxydopamine model of Parkinson's disease. Neurotox. Res. 11, 151-167. doi: 10.1007/BF03033565

Smith, A. D., Amalric, M., Koob, G. F., and Zigmond, M. J. (2002). Effect of bilateral 6-hydroxydopamine lesions of the medial forebrain bundle on reaction time. Neuropsychopharmacology 26, 756-764. doi: 10.1016/S0893-133X(01)00420-1

Solstad, T., Boccara, C. N., Kropff, E., Moser, M. B., and Moser, E. I. (2008). Representation of geometric borders in the entorhinal cortex. Science 322, 1865-1868. doi: 10.1126/science. 1166466

Stuber, G. D., Britt, J. P., and Bonci, A. (2012). Optogenetic modulation of neural circuits that underlie reward seeking. Biol. Psychiatry 71, 1061-1067. doi: 10.1016/j.biopsych.2011.11.010

Sullivan, R. M. (2004). Hemispheric asymmetry in stress processing in rat prefrontal cortex and the role of mesocortical dopamine. Stress 7, 131-143. doi: $10.1080 / 102538900410001679310$

Sullivan, R. M., and Dufresne, M. M. (2006). Mesocortical dopamine and HPA axis regulation: role of laterality and early environment. Brain Res. 1076, 49-59. doi: 10.1016/j.brainres.2005.12.100

Sullivan, R. M., and Gratton, A. (1998). Relationships between stress-induced increases in medial prefrontal cortical dopamine and plasma corticosterone levels in rats: role of cerebral laterality. Neuroscience 83, 81-91. doi: 10.1016/S03064522(97)00370-9

Sullivan, R. M., and Szechtman, H. (1995). Asymmetrical influence of mesocortical dopamine depletion on stress ulcer development and subcortical dopamine systems in rats: implications for psychopathology. Neuroscience 65, 757-766. doi: 10.1016/0306-4522(94)00531-9

Sumiyoshi, T., Tsunoda, M., Uehara, T., Tanaka, K., Itoh, H., Sumiyoshi, C., et al. (2004). Enhanced locomotor activity in rats with excitotoxic lesions of the entorhinal cortex, a neurodevelopmental animal model of schizophrenia: behavioral and in vivo microdialysis studies. Neurosci. Lett. 364, 124-129. doi: 10.1016/j.neulet.2004.04.027

Swanson, L. W. (1982). The projections of the ventral tegmental area and adjacent regions: a combined fluorescent retrograde tracer and immunofluorescence study in the rat. Brain Res. Bull. 9, 321-353. doi: 10.1016/0361-9230(82) 90145-9

Szostak, C., Jakubovic, A., Phillips, A. G., and Fibiger, H. C. (1986). Bilateral augmentation of dopaminergic and serotonergic activity in the striatum and nucleus accumbens induced by conditioned circling. J. Neurosci. 6, 2037-2044.

Szostak, C., Jakubovic, A., Phillips, A. G., and Fibiger, H. C. (1989). Neurochemical correlates of conditioned circling within localized regions of the striatum. Exp. Brain Res. 75, 430-440. doi: 10.1007/BF00247949

Szostak, C., Porter, L., Jakubovic, A., Phillips, A. G., and Fibiger, H. C. (1988). Conditioned circling in rats: bilateral involvement of the mesotelencephalic dopamine system demonstrated following unilateral 6-hydroxydopamine lesions. Neuroscience 26, 395-401. doi: 10.1016/0306-4522(88) 90157-1

Taber, M. T., and Fibiger, H. C. (1995). Electrical stimulation of the prefrontal cortex increases dopamine release in the nucleus accumbens of the rat: modulation by metabotropic glutamate receptors. J. Neurosci. 15, 3896-3904.

Thiel, C. M., and Schwarting, R. K. (2001). Dopaminergic lateralisation in the forebrain: relations to behavioural asymmetries and anxiety in male Wistar rats. Neuropsychobiology 43, 192-199. doi: 10.1159/000054889 
Thierry, A. M., Tassin, J. P., Blanc, G., and Glowinski, J. (1976). Selective activation of mesocortical DA system by stress. Nature 263, 242-244. doi: $10.1038 / 263242 \mathrm{a} 0$

Tomer, R., Goldstein, R. Z., Wang, G. J., Wong, C., and Volkow, N. D. (2008). Incentive motivation is associated with striatal dopamine asymmetry. Biol. Psychol. 77, 98-101. doi: 10.1016/j.biopsycho.2007.08.001

Tomer, R., Slagter, H. A., Christian, B. T., Fox, A. S., King, C. R., Murali, D., et al. (2014). Love to win or hate to lose? Asymmetry of dopamine D2 receptor binding predicts sensitivity to reward versus punishment. J. Cogn. Neurosci. 26, 1039-1048. doi: 10.1162/jocn_a_00544

Torres, E. M., and Dunnett, S. B. (2012). “6-OHDA lesion models of Parkinson's disease in the rat" in Animal Models of Movement Disorders, Vol. 2, eds E. L. Lane and S. B. Dunnett (New York, NY: Humana Press), 267-279. doi: 10.1007/9781-61779-301-1

Totterdell, S., and Meredith, G. E. (1997). Topographical organization of projections from the entorhinal cortex to the striatum of the rat. Neuroscience 78 , 715-729. doi: 10.1016/S0306-4522(96)00592-1

Uehara, T., Sumiyoshi, T., Matsuoka, T., Itoh, H., and Kurachi, M. (2007). Effect of prefrontal cortex inactivation on behavioral and neurochemical abnormalities in rats with excitotoxic lesions of the entorhinal cortex. Synapse 61, 391-400. doi: 10.1002/syn.20383

Uehara, T., Tanii, Y., Sumiyoshi, T., and Kurachi, M. (2000). Neonatal lesions of the left entorhinal cortex affect dopamine metabolism in the rat brain. Brain Res. 860, 77-86. doi: 10.1016/S0006-8993(00)01985-5

Ungerstedt, U., and Arbuthnott, G. W. (1970). Quantitative recording of rotational behavior in rats after 6-hydroxy-dopamine lesions of the nigrostriatal dopamine system. Brain Res. 24, 485-493. doi: 10.1016/0006-8993(70)90187-3

Van Der Kooy, D., Coscina, D. V., and Hattori, T. (1981). Is there a nondopaminergic nigrostriatal pathway? Neuroscience 6, 345-357. doi: 10.1016/ 0306-4522(81)90128-7

Van Der Kooy, D., and Wise, R. A. (1980). Retrograde fluorescent tracing of substantia nigra neurons combined with catecholamine histofluorescence. Brain Res. 183, 447-452. doi: 10.1016/0006-8993(80)90479-5

Van Dyck, C. H., Seibyl, J. P., Malison, R. T., Laruelle, M., Zoghbi, S. S., Baldwin, R. M., et al. (2002). Age-related decline in dopamine transporters: analysis of striatal subregions, nonlinear effects, and hemispheric asymmetries. Am. J. Geriatr. Psychiatry 10, 36-43. doi: 10.1097/00019442-200201000-00005

Van Zessen, R., Phillips, J. L., Budygin, E. A., and Stuber, G. D. (2012). Activation of VTA GABA neurons disrupts reward consumption. Neuron 73, 1184-1194. doi: 10.1016/j.neuron.2012.02.016

Veening, J. G., Cornelissen, F. M., and Lieven, P. A. (1980). The topical organization of the afferents to the caudatoputamen of the rat. A horseradish peroxidase study. Neuroscience 5, 1253-1268. doi: 10.1016/0306-4522(80)90198-0
Vernaleken, I., Weibrich, C., Siessmeier, T., Buchholz, H. G., Rosch, F., Heinz, A., et al. (2007). Asymmetry in dopamine $\mathrm{D}(2 / 3)$ receptors of caudate nucleus is lost with age. Neuroimage 34, 870-878. doi: 10.1016/j.neuroimage.2006. 10.013

Wichmann, T., and Delong, M. R. (1996). Functional and pathophysiological models of the basal ganglia. Curr. Opin. Neurobiol. 6, 751-758. doi: 10.1016/S09594388(96)80024-9

Wilson, C. J., and Groves, P. M. (1980). Fine structure and synaptic connections of the common spiny neuron of the rat neostriatum: a study employing intracellular inject of horseradish peroxidase. J. Comp. Neurol. 194, 599-615. doi: $10.1002 /$ cne. 901940308

Wise, R. A. (2002). Brain reward circuitry: insights from unsensed incentives. Neuron 36, 229-240. doi: 10.1016/S0896-6273(02)00965-0

Wurtz, R. H., and Hikosaka, O. (1986). Role of the basal ganglia in the initiation of saccadic eye movements. Prog. Brain Res. 64, 175-190. doi: 10.1016/S00796123(08)63412-3

Yamamoto, B. K., and Freed, C. R. (1982). The trained circling rat: a model for inducing unilateral caudate dopamine metabolism. Nature 298, 467-468. doi: $10.1038 / 298467 \mathrm{a} 0$

Yamamoto, B. K., and Freed, C. R. (1984a). Asymmetric dopamine and serotonin metabolism in nigrostriatal and limbic structures of the trained circling rat. Brain Res. 297, 115-119. doi: 10.1016/0006-8993(84)90547-X

Yamamoto, B. K., and Freed, C. R. (1984b). Reversal of amphetamine-induced circling preference in trained circling rats. Life Sci. 34, 675-682. doi: 10.1016/00243205(84)90232-7

Zimmerberg, B., Glick, S. D., and Jerussi, T. P. (1974). Neurochemical correlate of a spatial preference in rats. Science 185, 623-625. doi: 10.1126/science.185.4151.623

Conflict of Interest Statement: The authors declare that the research was conducted in the absence of any commercial or financial relationships that could be construed as a potential conflict of interest.

Received: 31 October 2013; accepted: 24 May 2014; published online: 11 June 2014. Citation: Molochnikov I and Cohen D (2014) Hemispheric differences in the mesostriatal dopaminergic system. Front. Syst. Neurosci. 8:110. doi: 10.3389/fnsys.2014.00110 This article was submitted to the journal Frontiers in Systems Neuroscience. Copyright (C) 2014 Molochnikov and Cohen. This is an open-access article distributed under the terms of the Creative Commons Attribution License (CC BY). The use, distribution or reproduction in other forums is permitted, provided the original author(s) or licensor are credited and that the original publication in this journal is cited, in accordance with accepted academic practice. No use, distribution or reproduction is permitted which does not comply with these terms. 